\title{
Análise do Desempenho Orçamentário e Financeiro do Município de Rio Acima-MG
}

\author{
Analysis of the Budget and Financial Performance of the Municipality of Rio Acima-MG \\ Análisis del Presupuesto y Desempeño Financiero del Municipio de Río Acima-MG
}

Recebido: 28/03/2021 | Revisado: 04/04/2021 | Aceito: 08/04/2021 | Publicado: 18/04/2021

\author{
Leny Pereira Neves \\ ORCID: https://orcid.org/0000-0002-5258-9553 \\ Universidade Federal dos Vales de Jequitinhonha e Mucuri, Brasil \\ E-mail: lennyneves33_@hotmail.com \\ Carlos Alberto Mirez Tarrillo \\ ORCID: https://orcid.org/0000-0003-3024-915X \\ Universidade Federal dos Vales de Jequitinhonha e Mucuri, Brasil \\ E-mail: carlos.mirez@ufvjm.edu.br \\ Nathalia Stockler Fialho Soares \\ ORCID: https://orcid.org/0000-0002-9667-3060 \\ Universidade Federal dos Vales de Jequitinhonha e Mucuri, Brasil \\ E-mail: nathaliastockler17@hotmail.com
}

\begin{abstract}
Resumo
Através do orçamento público, os gestores são capazes de controlar as contas públicas destinando de forma eficaz e eficiente os recursos disponíveis para o município realizar suas atividades e obter o desejável desenvolvimento. Este artigo tem como objetivo analisar o desempenho orçamentário e financeiro do município de Rio Acima - MG. O período de análise compreende os anos de 2015 a 2018 e utilizou-se técnicas de análise vertical e horizontal. Os dados foram buscados junto ao Tesouro Nacional e na Fundação João Pinheiro. Com relação à análise vertical das receitas correntes, ocorreu uma oscilação leve no período analisado. A análise horizontal das transferências correntes demonstra que essa categoria sofreu leve queda. $\mathrm{Na}$ análise dos dados do município, foi possível perceber que assim como os outros municípios pequenos brasileiros, Rio Acima/MG sobrevive prioritariamente de recursos provenientes da União e do Estado. Também é possível perceber que existem variações negativas no ano de 2017, o que pode ser explicado pela crise política e econômica vivida no país nesse período. A presente análise possibilita uma melhoria na tomada de decisão dos gestores municipais que poderão destinar os recursos disponíveis de forma consciente e exata.
\end{abstract}

Palavras-chave: Orçamento público; Finanças públicas; Administração pública.

\begin{abstract}
Through the public budget, managers are able to control public accounts, effectively and efficiently allocating the resources available to the municipality to carry out its activities and obtain the desirable development. This article aims to analyze the budgetary and financial performance of the municipality of Rio Acima - MG. The analysis period comprises the years 2015 to 2018 and vertical and horizontal analysis techniques were used. The data were obtained from the National Treasury and the João Pinheiro Foundation. Regarding the vertical analysis of current revenues, a slight oscillation occurred in the analyzed period. Horizontal analysis of current transfers demonstrates that this category has undergone light fall. In the analysis of the data of the municipality, it was possible to realize that as well as the other small Brazilian municipalities, Rio Above / MG survives primarily of resources from the Union and the State. It is also possible to notice that there are negative variations in 2017, which can be explained by the political and economic crisis experienced in the country during this period. This analysis allows an improvement in the decision-making of municipal managers who can allocate the available resources consciously and accurately.
\end{abstract}

Keywords: Public budget; Public finance; Public administration.

\section{Resumen}

A través del presupuesto público, los gestores pueden controlar las cuentas públicas asignando de forma eficaz y eficiente los recursos de que dispone el municipio para llevar a cabo sus actividades y alcanzar el desarrollo deseable. Este artículo tiene como objetivo analizar el desempeño presupuestario y financiero del municipio de Río Acima - MG. El periodo de análisis comprende los años 2015 a 2018 y se han utilizado técnicas de análisis vertical y horizontal. Los datos se obtuvieron del Tesoro Nacional y de la Fundação João Pinheiro. En cuanto al análisis vertical de los ingresos corrientes, se observa una ligera oscilación en el periodo analizado. El análisis horizontal de las transferencias corrientes muestra que esta categoría sufrió un ligero descenso. En el análisis de los datos del municipio, se pudo constatar que, al igual que otros pequeños municipios brasileños, Río Acima/MG sobrevive principalmente con recursos de la Unión y del Estado. También se puede notar que hay variaciones negativas en el año 2017, lo que se puede explicar por la crisis 
política y económica que se vivió en el país en este periodo. Este análisis permite mejorar el proceso de toma de decisiones de los gestores municipales, que podrán asignar los recursos disponibles de forma consciente y precisa.

Palabras clave: Presupuesto público; Finanzas públicas; Administración pública.

\section{Introdução}

Segundo Faustino (2018), planejar e gerir a máquina pública tem sido ferramenta fundamental para obtenção de resultados eficazes, que produzem maiores ganhos para a gestão pública, no geral. "A busca por ferramentas inovadoras formou o que chamamos hoje de governança pública" (Peters, 2013, p.28).

Segundo Santos (2012), o Orçamento Público reúne um conjunto de receitas e despesas, sendo assim não apenas um instrumento contábil, mas fundamentalmente um instrumento político de alocação de recursos econômicos e sociais entre o governo e a sociedade. Através do orçamento público, os gestores são capazes de controlar as contas públicas destinando de forma eficaz e eficiente os recursos disponíveis para o município realizar suas atividades e obter o desejável desenvolvimento. A Lei de Responsabilidade Fiscal (LRF) é um instrumento que obriga os responsáveis pela administração pública a disponibilizar virtualmente, além do orçamento público, todos os demais instrumentos que compõem o sistema orçamentário, como o Plano Plurianual, a Lei de Diretrizes Orçamentárias (LDO), os relatórios de execução, os balanços anuais, etc.

Para Kohama (2014) a lei dos orçamentos anuais é o instrumento utilizado para a consequente materialização do conjunto de ações e objetivos que foram planejados visando ao melhor atendimento e bem-estar da coletividade. Já Linhares et al (2012), acreditam que a LRF incentivou atitudes mais responsáveis pelos gestores municipais, fazendo com que busquem aumentar sua arrecadação e gastar os recursos de forma mais consciente. Segundo Moreira (2013) a Lei de Responsabilidade Fiscal e o Controle Interno convergem para o implemento de ações planejadas e transparentes, com procedimentos de gestão administrativa, voltados à obtenção do equilíbrio orçamentário e financeiro.

Com o orçamento a alocação de recursos se torna mais inteligente, visto que a destinação de gastos é prevista e as despesas fixadas. Por meio da Análise das Demonstrações Contábeis, pode-se trabalhar na construção de um conjunto de indicadores capazes de transmitir informações importantes sobre a administração orçamentária e financeira do município, auxiliando assim o gestor no processo de tomada de decisão.

Para Grzybowski et al (2016), a excelência da gestão dos recursos se encontra atrelada a eficiência, eficácia e efetividade, ou seja, minimizar os custos e direcionar todas as energias para a qualidade dos produtos e serviços.

Segundo Silva et al (2017), avaliar eficiência no setor público torna-se um desafio para a Ciência Contábil, dado que na sua função social é imperativo prestar informação para a tomada de decisão e para o processo de operacionalização do controle social no sentido de suprir as necessidades da coletividade.

Oliveira e Reis apud Teixeira (2019) reforçam que "avaliar eficiência, eficácia e efetividade das estruturas, processos e resultados relacionados ao risco, a vulnerabilidades, ao acesso e à satisfação dos cidadãos torna-se ferramenta central na apropriação do planejamento para o aperfeiçoamento do sistema".

Esta pesquisa objetiva analisar a dinâmica entre a receita $\mathrm{x}$ despesa juntamente com o equilíbrio orçamentário do município de Rio Acima/MG, analisando e avaliando o planejamento e execução orçamentária deste ente.

Os dados orçamentários para as análises feitas no presente estudo são provenientes de dados coletados no sistema do Tesouro Nacional e na Fundação João Pinheiro, com a realização de análise vertical e horizontal. Os balanços públicos analisados são referentes aos anos de 2015, 2016, 2017 e 2018. 


\section{Metodologia}

Como procedimento metodológico, a abordagem do problema se caracteriza como uma pesquisa quali-quantitativa. Quanto aos objetivos, se trata de uma pesquisa descritiva. Para Gil (2008) a pesquisa descritiva tem como objetivo primordial descrever as características de determinada população ou fenômeno ou o estabelecimento de relações entre variáveis, sendo muito significativo a utilização de técnicas de coleta de dados. Essas pesquisas, junto das exploratórias, são bastante usuais por pesquisadores sociais que se preocupam com a atuação prática. Para formular o referencial teórico, foi utilizada a pesquisa bibliográfica, partindo de fontes já publicados. Em relação aos procedimentos técnicos abordados, a pesquisa se dará por um estudo de caso, a qual realizará um estudo relativo à avaliação de relatórios contábeis disponíveis no site do Tesouro Nacional e Fundação João Pinheiro. Para a construção das tabelas e gráficos, foi utilizado o software Microsoft Excel. Usando recursos gráficos nesta pesquisa, foi possível interpretar essas informações de forma visual e espacial e, com isso, auferir afirmações e conclusão com base lógica.

\section{Resultados e Discussão}

\subsection{Breve Histórico do Município de Rio Acima/MG}

O município de Rio Acima se localiza na região metropolitana de Belo Horizonte e distante 34 quilômetros da capital mineira, como mostra a Figura 1. De acordo com as estimativas do IBGE, em 2020 o município possuía 10.420 habitantes (IBGE, 2018). Os municípios confinantes de Rio Acima são Itabirito, Caeté e Ouro Preto.

Em 2016 a média de salário do município era de 2,4 salários mínimos e a porcentagem de pessoas ocupadas em relação a quantidade de habitantes era de 18,8\% (IBGE, 2018).

A taxa de mortalidade infantil é de 15,5 para 1000 nascidos vivos, ou seja, 1,55\%. Em relação a internações ocasionadas por diarreia, o percentual é de 0,03\% (IBGE, 2018). Em relação ao sanitarismo, 83,6\% de todos os municípios possuem esgotamento sanitário adequado, ficando na posição 166 na listagem dos 853 municípios mineiros (IBGE, 2018).

$\mathrm{Na}$ economia o município apresenta o produto interno bruto (PIB) a preços correntes de $\mathrm{R} \$ 85.513 .750,00$. Os impostos líquidos de subsídios sobre produtos e a preços correntes representa $\mathrm{R} \$ 6.885 .824,00$. Já o valor adicionado bruto a preços correntes da indústria representa $\mathrm{R} \$ 23.821 .484,00$. Para a agropecuária é de $\mathrm{R} \$ 275.783,00$ e para serviços é de $\mathrm{R} \$ 54.530 .659,00$.

Figura 1 - Localização do município de Rio Acima - MG.

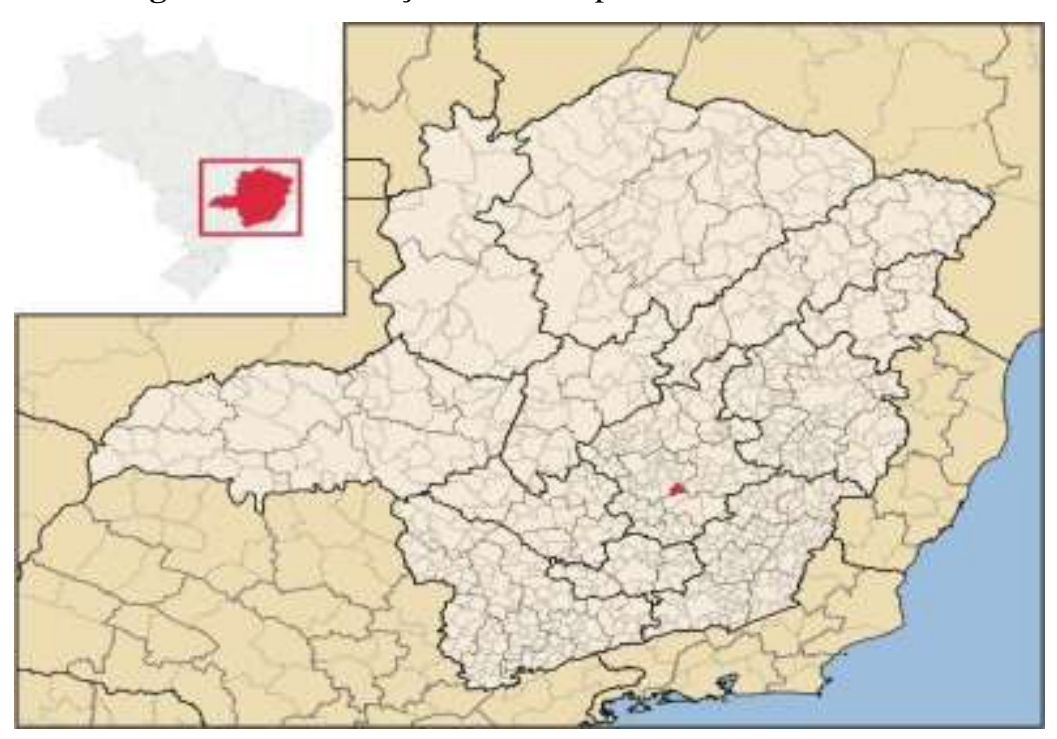

Fonte: IBGE (2021). 


\subsection{Análise Orçamentária e Financeira do Município}

Através das análises verticais, horizontais e dos índices de balanços orçamentários, foi possível avaliar o desempenho do município Rio Acima - MG no período de 2015 a 2018. Com esse tipo de análise pode-se observar a dinâmica de arrecadação e distribuição dos recursos do município e sua capacidade de administração eficiente.

\subsubsection{Análise Vertical e Horizontal dos Balanços}

Através da Tabela 1 podemos analisar as receitas e despesas de cada categoria econômica do município durante o período estudado.

Tabela 1 - Receitas e despesas por categoria econômica do município de Rio Acima (2015-2018).

\begin{tabular}{|c|c|c|c|c|c|c|c|c|c|c|c|}
\hline RECEITAS & 2015 & AV\% & 2016 & AV\% & AH\% & 2017 & AV\% & AH\% & 2018 & AV\% & AH\% \\
\hline Receitas Correntes & $\begin{array}{c}38.599 .258 \\
, 16\end{array}$ & $\begin{array}{c}100,0 \\
0\end{array}$ & $\begin{array}{c}44.676 .438 \\
, 73\end{array}$ & 99,24 & $\begin{array}{c}115 \\
74\end{array}$ & $\begin{array}{c}43.684 .887 \\
, 49\end{array}$ & 100,00 & $\begin{array}{c}113 \\
18\end{array}$ & $\begin{array}{c}45.021 .90 \\
5,17\end{array}$ & 95,61 & 116,64 \\
\hline Receita Tributária & $\begin{array}{c}4.772 .903 \\
94\end{array}$ & 12,37 & $\begin{array}{c}4.104 .648, \\
76\end{array}$ & 9,12 & $\begin{array}{c}86,0 \\
0\end{array}$ & $\begin{array}{c}4.454 .429 \\
62\end{array}$ & 10,20 & $\begin{array}{c}93,3 \\
3\end{array}$ & $\begin{array}{c}5.110 .615 \\
, 11\end{array}$ & 10,85 & 107,08 \\
\hline $\begin{array}{l}\text { Receitas de } \\
\text { Contribuições }\end{array}$ & $621.985,26$ & 1,61 & $\begin{array}{c}1.544 .647 \\
19\end{array}$ & 3,43 & $\begin{array}{c}248 \\
34\end{array}$ & $652.507,23$ & 1,49 & $\begin{array}{c}104, \\
91\end{array}$ & $\begin{array}{c}2.373 .843 \\
, 90\end{array}$ & 5,04 & 381,66 \\
\hline Receita Patrimonial & $189.606,60$ & 0,49 & $444.560,14$ & 0,99 & $\begin{array}{c}234, \\
46\end{array}$ & $370.407,12$ & 0,85 & $\begin{array}{c}195, \\
36\end{array}$ & $\begin{array}{c}306.440,3 \\
1 \\
\end{array}$ & 0,65 & 161,62 \\
\hline $\begin{array}{l}\text { Receita } \\
\text { Agropecuária }\end{array}$ & 0,00 & 0,00 & 0,00 & 0,00 & 0,00 & 0,00 & 0,00 & 0,00 & 0,00 & 0,00 & 0,00 \\
\hline Receita Industrial & 0,00 & 0,00 & 0,00 & 0,00 & 0,00 & 0,00 & 0,00 & 0,00 & 0,00 & 0,00 & 0,00 \\
\hline Receita de Serviços & 0,00 & 0,00 & $345.250,08$ & 0,77 & 0,00 & 0,00 & 0,00 & 0,00 & 0,00 & 0,00 & 0,00 \\
\hline $\begin{array}{l}\text { Transferências } \\
\text { Correntes }\end{array}$ & $\begin{array}{c}32.619 .799 \\
, 66\end{array}$ & 84,51 & $\begin{array}{c}37.877 .420 \\
, 91\end{array}$ & 84,14 & $\begin{array}{c}116, \\
12\end{array}$ & $\begin{array}{c}37.838 .385 \\
, 86\end{array}$ & 86,62 & $\begin{array}{c}116, \\
00\end{array}$ & $\begin{array}{c}37.205 .51 \\
3,53\end{array}$ & 79,01 & 114,06 \\
\hline $\begin{array}{l}\text { Outras Receitas } \\
\text { Correntes }\end{array}$ & $394.962,70$ & 1,02 & $359.911,65$ & 0,80 & $\begin{array}{c}91,1 \\
3\end{array}$ & $369.157,66$ & 0,85 & $\begin{array}{c}93,4 \\
7\end{array}$ & $25.492,32$ & 0,05 & 6,45 \\
\hline Receitas de Capital & 0,00 & 0,00 & $340.822,51$ & 0,76 & 0,00 & 0,00 & 0,00 & 0,00 & $\begin{array}{c}2.065 .090 \\
, 70\end{array}$ & 4,39 & 0,00 \\
\hline $\begin{array}{l}\text { Operações de } \\
\text { Crédito }\end{array}$ & 0,00 & 0,00 & 0,00 & 0,00 & 0,00 & 0,00 & 0,00 & 0,00 & 0,00 & 0,00 & 0,00 \\
\hline Alienação de Bens & 0,00 & 0,00 & 0,00 & 0,00 & 0,00 & 0,00 & 0,00 & 0,00 & 0,00 & 0,00 & 0,00 \\
\hline $\begin{array}{l}\text { Amortização de } \\
\text { Empréstimos }\end{array}$ & 0,00 & 0,00 & 0,00 & 0,00 & 0,00 & 0,00 & 0,00 & 0,00 & 0,00 & 0,00 & 0,00 \\
\hline $\begin{array}{l}\text { Transferências de } \\
\text { Capital }\end{array}$ & 0,00 & 0,00 & 0,00 & 0,00 & 0,00 & 0,00 & 0,00 & 0,00 & $\begin{array}{c}445.023,1 \\
3\end{array}$ & 0,95 & 0,00 \\
\hline $\begin{array}{l}\text { Outras Receitas de } \\
\text { Capital }\end{array}$ & 0,00 & 0,00 & 0,00 & 0,00 & 0,00 & 0,00 & 0,00 & 0,00 & 0,00 & 0,00 & 0,00 \\
\hline $\begin{array}{l}\text { Receitas Intra- } \\
\text { Orçamentárias } \\
\text { Corrente + Capital } \\
\end{array}$ & 0,00 & 0,00 & $340.822,51$ & 0,76 & 0,00 & 0,00 & 0,00 & 0,00 & $\begin{array}{c}1.620 .067 \\
, 57\end{array}$ & 3,44 & 0,00 \\
\hline RECEITA TOTAL & $\begin{array}{c}38.599 .258 \\
, 16\end{array}$ & $\begin{array}{c}100,0 \\
0 \\
\end{array}$ & $\begin{array}{c}45.017 .261 \\
, 24\end{array}$ & $\begin{array}{c}100,0 \\
0 \\
\end{array}$ & $\begin{array}{c}116 \\
63\end{array}$ & $\begin{array}{c}43.684 .887 \\
, 49\end{array}$ & 100,00 & $\begin{array}{c}113, \\
18\end{array}$ & $\begin{array}{c}47.086 .99 \\
5,87 \\
\end{array}$ & $\begin{array}{c}100,0 \\
0\end{array}$ & 121,99 \\
\hline DESPESAS & 2015 & AV\% & 2016 & AV\% & AH\% & 2017 & AV\% & $\mathrm{AH} \%$ & 2018 & AV\% & АH\% \\
\hline Despesas Correntes & $\begin{array}{c}37.823 .636 \\
, 51\end{array}$ & 96,45 & $\begin{array}{l}44.595 .084 \\
, 00\end{array}$ & 98,43 & 117,90 & $\begin{array}{c}32.857 .754 \\
, 80\end{array}$ & 92,14 & $\begin{array}{c}86,8 \\
7\end{array}$ & $\begin{array}{c}45.997 .75 \\
2,78\end{array}$ & 94,62 & 121,61 \\
\hline $\begin{array}{l}\text { Pessoal e Encargos } \\
\text { Sociais }\end{array}$ & $\begin{array}{c}26.024 .707 \\
, 10\end{array}$ & 66,36 & $\begin{array}{c}31.002 .566 \\
, 26\end{array}$ & 68,43 & 119,13 & $\begin{array}{c}21.496 .913 \\
, 75\end{array}$ & 60,28 & $\begin{array}{c}82,6 \\
0\end{array}$ & $\begin{array}{c}28.645 .14 \\
3,44\end{array}$ & 58,92 & 110,07 \\
\hline
\end{tabular}




\begin{tabular}{|c|c|c|c|c|c|c|c|c|c|c|c|}
\hline $\begin{array}{l}\text { Juros e Encargos da } \\
\text { Dívida }\end{array}$ & $27.600,49$ & 0,07 & $57.885,82$ & 0,13 & 209,73 & $151.011,62$ & 0,42 & $\begin{array}{c}547, \\
13\end{array}$ & $\begin{array}{c}239.377,2 \\
7\end{array}$ & 0,49 & 867,29 \\
\hline $\begin{array}{l}\text { Outras Despesas } \\
\text { Correntes }\end{array}$ & $\begin{array}{c}11.771 .328 \\
, 92\end{array}$ & 30,02 & $\begin{array}{c}13.534 .631 \\
, 92\end{array}$ & 29,87 & 114,98 & $\begin{array}{c}11.209 .829 \\
, 43\end{array}$ & 31,43 & $\begin{array}{c}95,2 \\
3\end{array}$ & $\begin{array}{c}17.113 .23 \\
2,07\end{array}$ & 35,20 & 145,38 \\
\hline Despesas de Capital & $1.392 .126,73$ & 3,55 & $712.867,16$ & 1,57 & 51,21 & $\begin{array}{c}2.803 .774 \\
36\end{array}$ & 7,86 & $\begin{array}{c}201, \\
40\end{array}$ & $\begin{array}{c}2.617 .445 \\
, 49\end{array}$ & 5,38 & 188,02 \\
\hline Investimentos & $852.853,84$ & 2,17 & $225.163,89$ & 0,50 & 26,40 & $\begin{array}{c}\text { 1.843.347, } \\
81\end{array}$ & 5,17 & $\begin{array}{c}216, \\
14\end{array}$ & $\begin{array}{c}1.390 .246 \\
, 39 \\
\end{array}$ & 2,86 & 163,01 \\
\hline $\begin{array}{l}\text { Inversões } \\
\text { Financeiras }\end{array}$ & 0,00 & 0,00 & 0,00 & 0,00 & 0,00 & 0,00 & 0,00 & 0,00 & 0,00 & 0,00 & 0,00 \\
\hline $\begin{array}{l}\text { Amortização da } \\
\text { Dívida }\end{array}$ & $539.272,89$ & 1,38 & $487.703,27$ & 1,08 & 90,44 & $960.426,55$ & 2,69 & 178,10 & $\begin{array}{c}1.227 .199 \\
, 10\end{array}$ & 2,52 & 227,57 \\
\hline DESPESA TOTAL & $\begin{array}{c}39.215 .763,2 \\
4\end{array}$ & 100,00 & $\begin{array}{c}45.307 .951,1 \\
6\end{array}$ & 100,00 & 115,54 & $\begin{array}{c}35.661 .529 \\
, 16\end{array}$ & 100,00 & 90,94 & $\begin{array}{c}48.615 .19 \\
8,27\end{array}$ & 100,00 & 123,97 \\
\hline
\end{tabular}

Fonte: DCA-Anexo I-C e Anexo I-D, Balanço Orçamentário extraído do https://siconfi.tesouro.gov.br

A Tabela 1 aponta uma oscilação tímida nas receitas correntes durante o período analisado. De 2015 para 2016 houve um pequeno acréscimo de aproximadamente R\$6mi. Já de 2016 para 2017 ocorreu uma leve queda na arrecadação de aproximadamente R \$1mi. Entre o ano de 2017 para 2018 ocorreu uma alta nas receitas correntes de aproximadamente R $\$ 2 \mathrm{mi}$. Por fim, comparando o primeiro ano com o último ano houve um ganho na receita. Com relação às despesas correntes, ocorreu o mesmo fator das receitas. Do ano de 2015 para 2016 houve um aumento nas despesas. De 2016 para 2017 ocorreu uma leve queda. No último período do ano de 2017 para 2018 ocorreu novamente uma alta.

Com relação à análise vertical das receitas correntes, ocorreu uma oscilação leve no período analisado. Iniciando com 100\% para o ano de 2015 ocorreu uma queda mesmo que leve para 99,24\% no ano de 2016. Posteriormente, em 2017 atingiu 100\% novamente. Entretanto, no ano de 2018 registrou 95,61\% como mostra o Gráfico 1.

Gráfico 1 - Análise Vertical das Receitas Correntes (2015-2018).

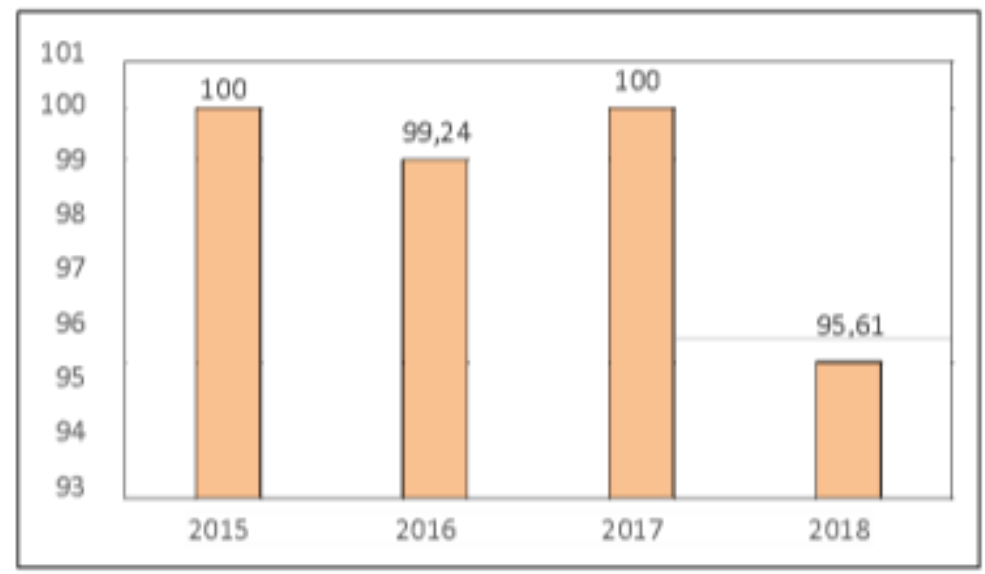

Fonte: Autores (2020).

Com relação às transferências correntes, o Gráfico 2 apresenta o desenvolvimento. 
Gráfico 2 - Análise Vertical das Transferências Correntes (2015-2018)

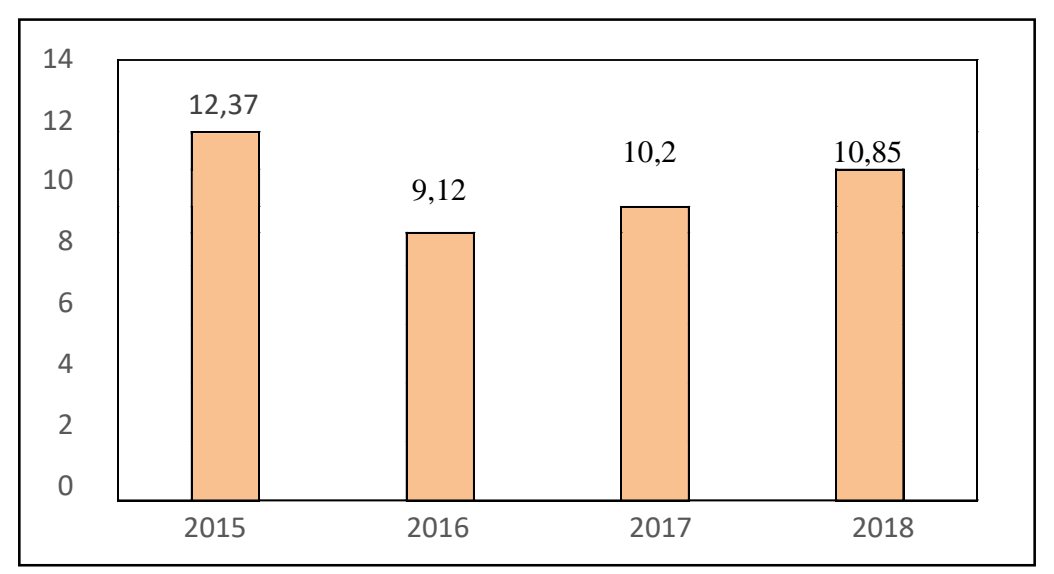

Fonte: Autores (2020)

Para esse município as transferências correntes são os maiores valores encontrados na análise orçamentária. Sendo assim, qualquer alteração positiva ou negativa desse parâmetro influência de forma significativa no desenvolvimento do mesmo. No período entre 2015 e 2016 houve uma leve queda de 0,37\%. Posteriormente, de 2016 para 2017 houve um crescimento de 2,48\%. Entretanto, de 2017 para 2018 ocorreu uma brusca queda de 7,61\%.

As receitas tributárias representam uma fonte que se pode dizer mais importante em tese para qualquer município. O Gráfico 3 apresenta o desenvolvimento durante o período.

Gráfico 3 - Análise Vertical das Receitas Tributárias (2015-2018).

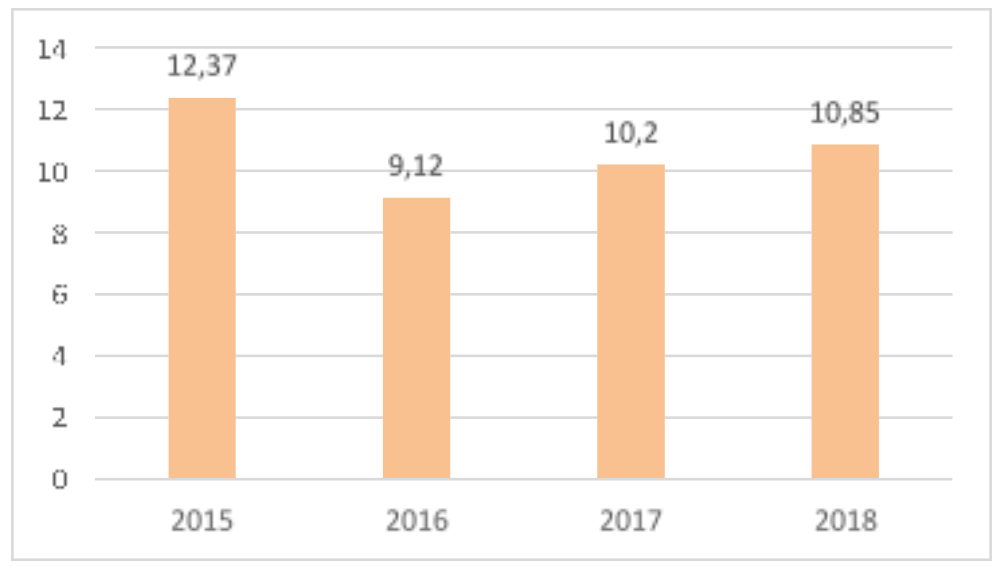

Fonte: Autores (2020).

Com o Gráfico 4 podemos obter a análise horizontal das receitas correntes do município. A categoria “Outras receitas correntes”, apresenta leve ascensão do ano de 2016 ao ano de 2017. Entretanto, ocorreu uma drástica queda no ano de 2018. Enquanto que em 2017 atingia 93,47\%, no ano de 2018 caiu para 6,45\%. A categoria Transferências correntes oscilou de forma tímida. No ano de 2016 estava em 116,12\% atingindo 116\% em 2017 e 114,06\% em 2018. Já a categoria Receita patrimonial sofreu sucessiva queda no decorrer do período. Em 2016 estava em 234,46\%, caindo para 195,36\% em 2017 e caindo novamente em 2018 atingindo 161,62\%. Com relação à categoria Receitas de contribuição, ocorreu uma queda e posteriormente uma alta. Em 2016 estava em 248,34. Já em 2017 caiu bastante atingindo 104,91 e subindo de forma vertiginosa em 2018 para $381,66$. 
Por fim, a categoria Receita tributária oscilou timidamente de forma positiva durante os anos. Em 2016 estava em 86\%. No ano de 2017 atingiu 93,33 e em 2018 107,08.

Gráfico 4 - Análise Horizontal das Receitas Correntes (2015-2018).

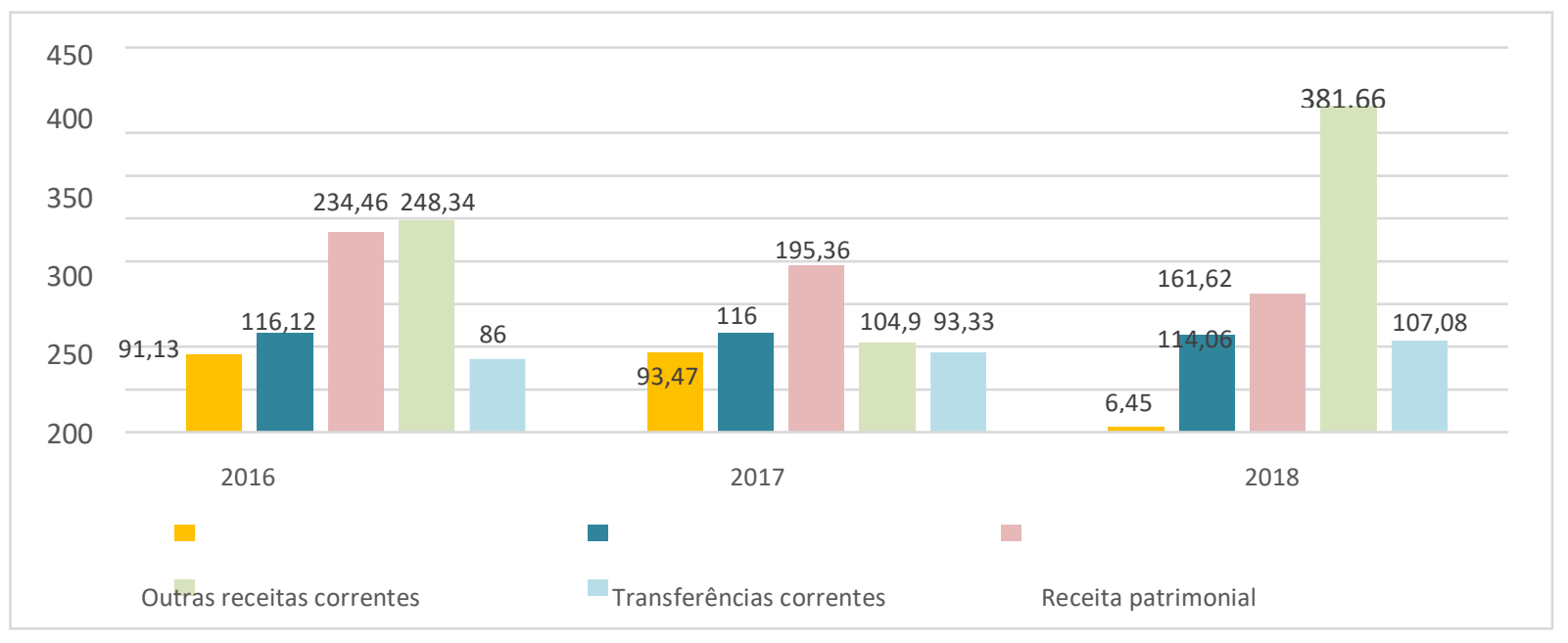

Fonte: Autores (2020).

A análise horizontal das transferências correntes está demonstrada no Gráfico 5. É possível identificar que essa categoria sofreu leve queda no período estudado. Em 2016 apresentava 116,12\%, caindo para 116\% em 2017 e chegando a $114,06 \%$ em 2018. O ano base o valor e reais era de $\mathrm{R} \$ 32 \mathrm{mi}$ aproximadamente.

Gráfico 5 - Análise Horizontal das Transferências Correntes (2015-2018).

\begin{tabular}{|c|c|c|c|}
\hline 116,50 & 116,12 & \multicolumn{2}{|l|}{116,00} \\
\hline \multicolumn{4}{|l|}{115,50} \\
\hline \multicolumn{4}{|l|}{115,00} \\
\hline \multicolumn{4}{|l|}{114,50} \\
\hline & & & 114,06 \\
\hline \multicolumn{4}{|l|}{113,50} \\
\hline \multicolumn{4}{|l|}{113,00} \\
\hline & 2016 & 2017 & 2018 \\
\hline
\end{tabular}

Fonte: Autores (2020).

Com relação a análise horizontal das receitas tributárias, o Gráfico 6 apresenta o desenvolvimento. Nessa categoria percebe-se que houve um leve acréscimo com o passar dos anos. O ano base era de aproximadamente $\mathrm{R} \$ 4,7 \mathrm{mi}$. Em 2016 houve uma queda para $\mathrm{R} \$ 4,1 \mathrm{mi}$ e em $2017 \mathrm{R} \$ 4,4 \mathrm{mi}$. No ano de 2018 subiu novamente atingindo $\mathrm{R} \$ 5,1 \mathrm{mi}$. 
Research, Society and Development, v. 10, n. 4, e46410414384, 2021

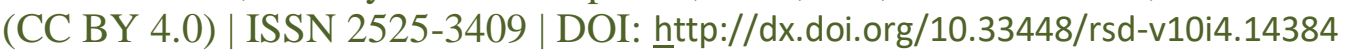

Gráfico 6 - Análise Horizontal das Receitas Tributárias (2015-2018).

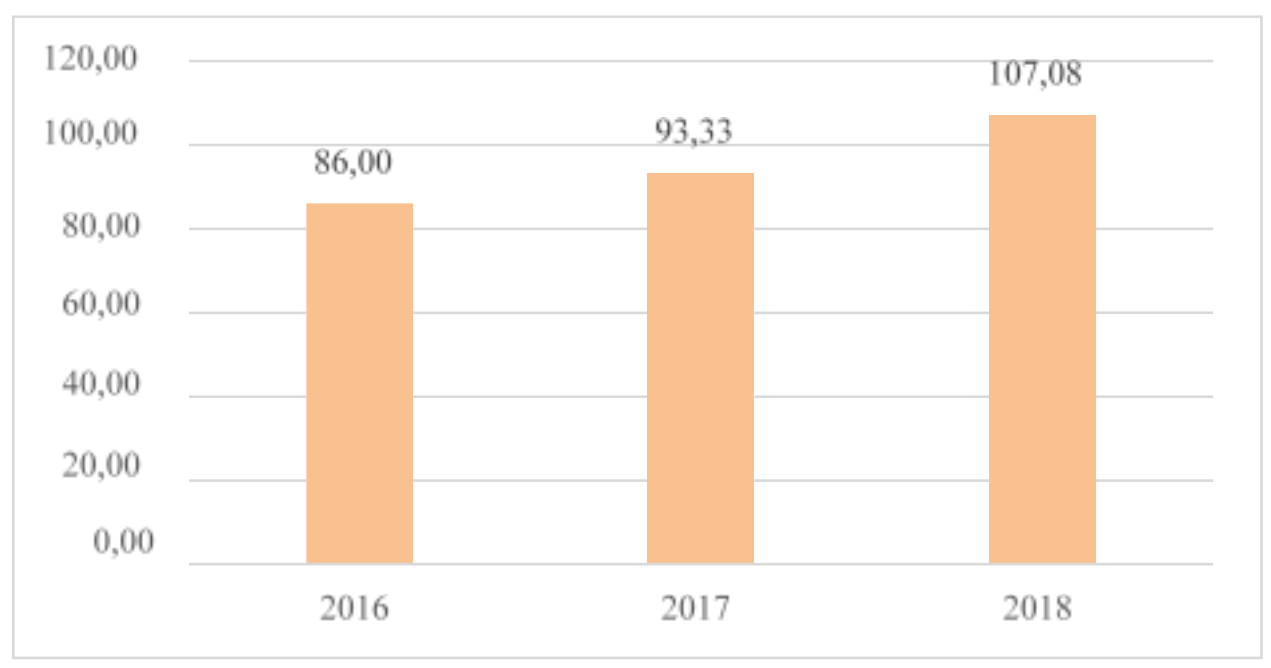

Fonte: Autores, 2020

O Gráfico 7 apresenta a análise vertical de despesas de pessoal e encargos sociais. Nessa categoria houve uma grande oscilação durante o período. Iniciando 2015 com 66,36\% subiu para 68,43\% em 2016. Ocorreu então uma queda em 2017 para 60,28\% caindo novamente em 2018 para 58,92\%.

Gráfico 7 - Análise Vertical de Despesas de Pessoal e Encargos Sociais (2015-2018).

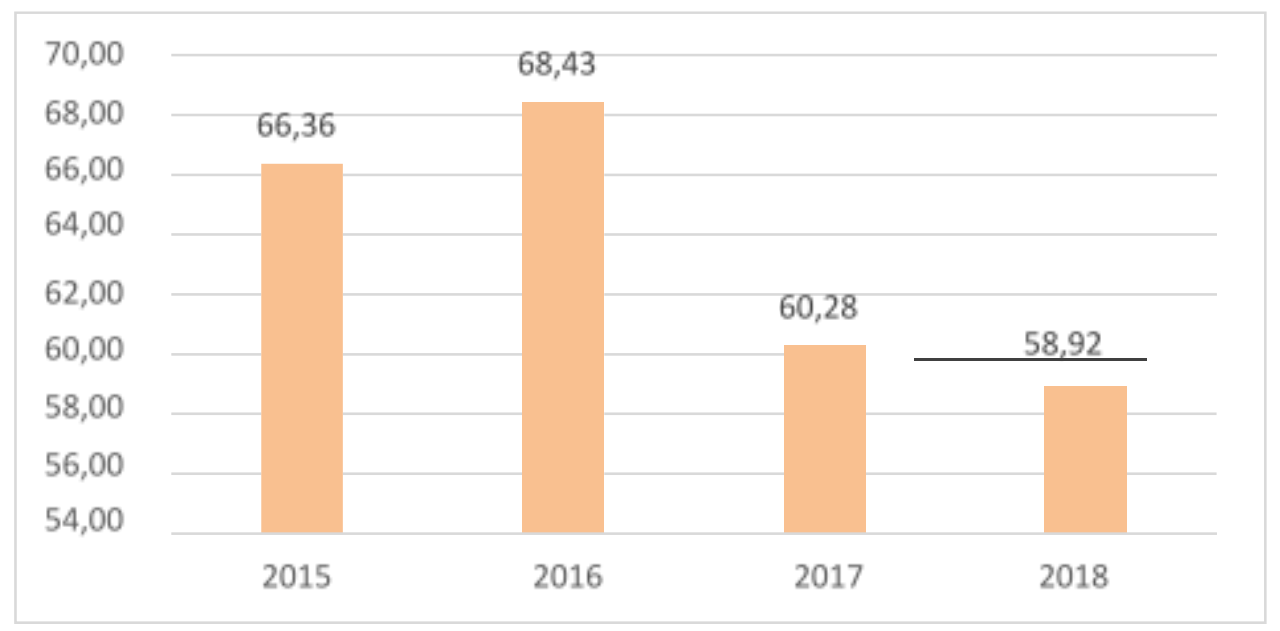

Fonte: Autores (2020)

Para as despesas correntes, o Gráfico 8 apresenta os valores obtidos. É possível perceber que no ano de 2017 houve um pico nas três categorias analisadas. Para outras despesas correntes quase que dobrou. Os Juros e encargos da dívida subiram incríveis 574,53\%. A categoria Pessoal e encargos sociais também cresceu vertiginosamente atingindo 596,56\%. 
Gráfico 8 - Análise Horizontal das Despesas Correntes (2015-2018).

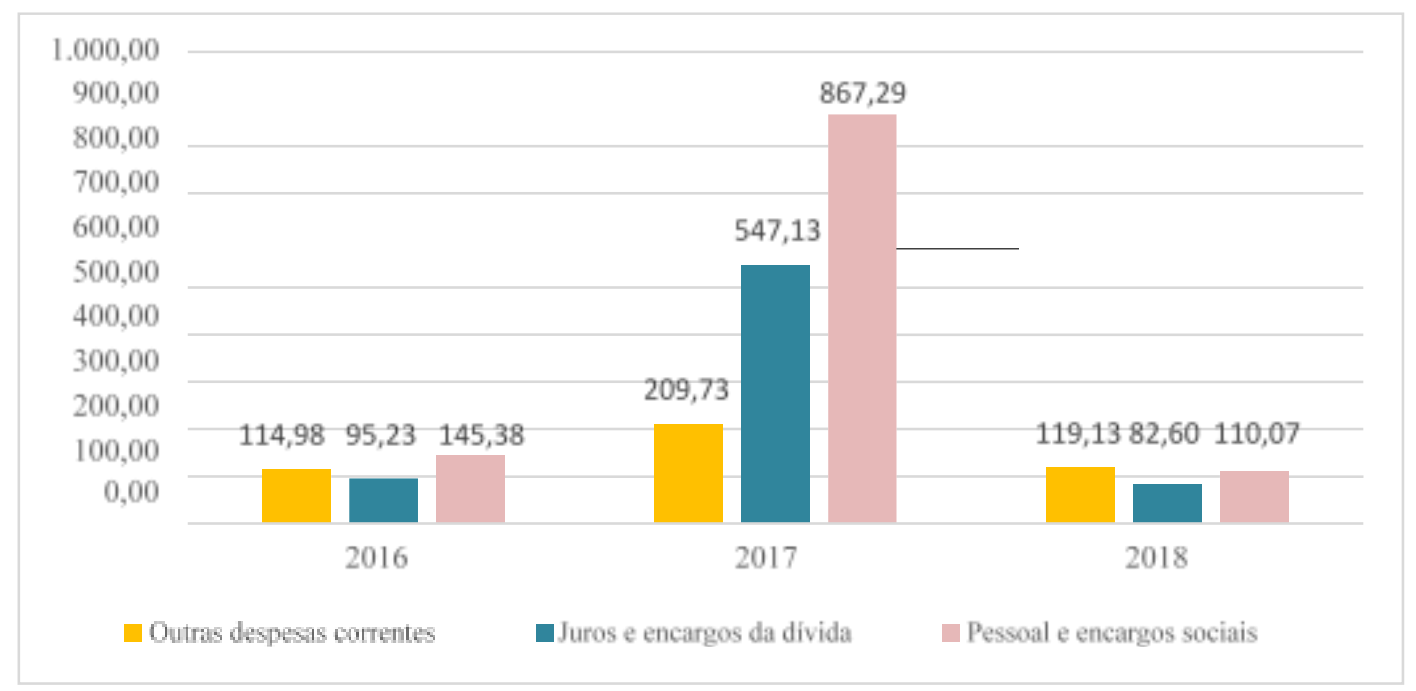

Fonte: Autores (2020).

As despesas de capital envolvem a amortização da dívida e investimentos. Muitas vezes o município alterna entre investir ou amortizar suas dívidas. O Gráfico 9 apresenta esse desempenho. De 2016 para 2017 os investimentos quase que subiram na ordem de dez vezes, enquanto que a amortização da dívida quase que dobrou. Do ano de 2017 para 2018 ocorreu uma queda indo de 216,14\% para 163,01\%. A amortização da dívida no mesmo período teve uma alta, indo de $178,1 \%$ para $227,57 \%$. Não houveram inversões financeiras durante esse período.

Gráfico 9 - Análise Horizontal das Despesas de Capital (2015-2018).

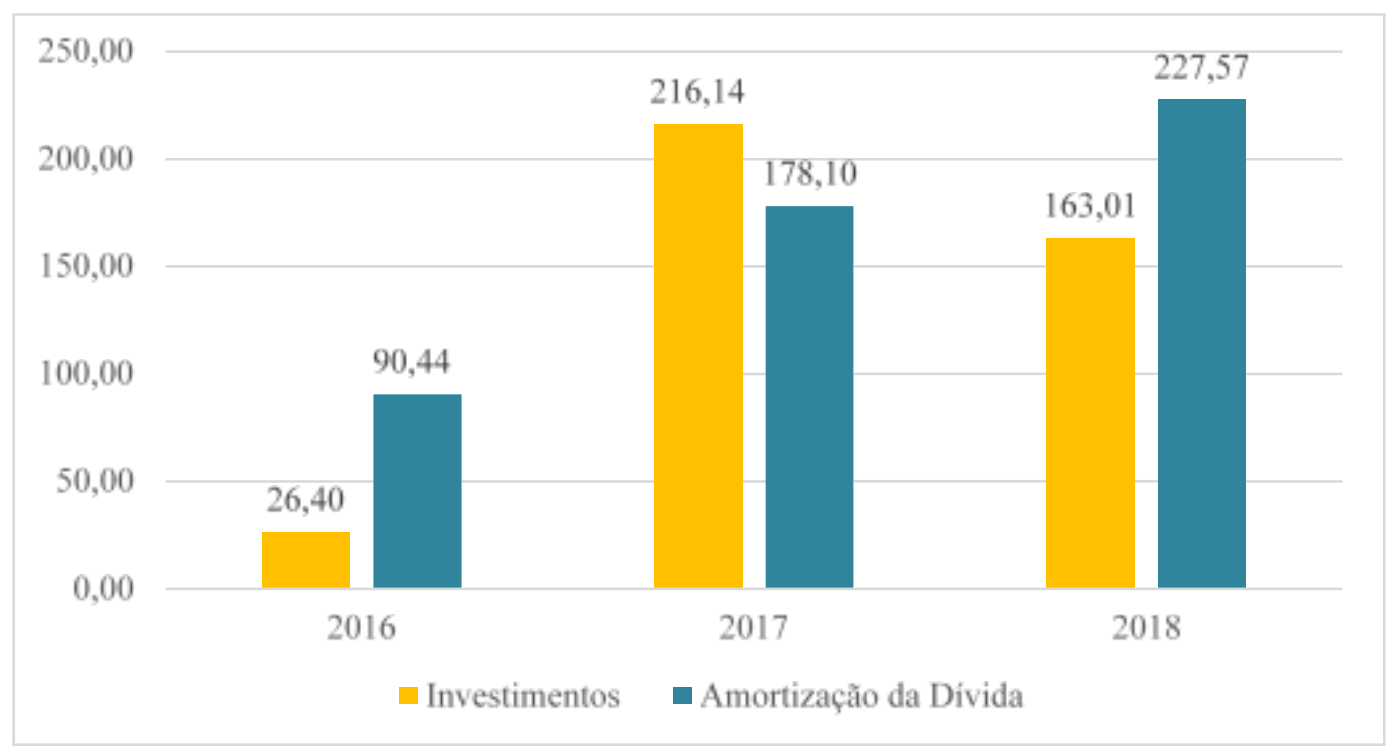

Fonte: Autores (2020)

\subsubsection{Despesas por Função do Governo}

Com relação à discriminação por funções do governo, a Tabela 2 apresenta todas as despesas do governo de forma separada. É possível perceber que durante todo o período avaliado a categoria Saúde é a que mais recebe recursos. A categoria 
representa 29,19\%, 26,36\%, 29,76\% e 25,87\% sucessivamente. Logo a seguir temos Educação. Em terceiro lugar temos a Administração.

Tabela 2 - Despesas por função de governo do município de Rio Acima (2015-2018)

\begin{tabular}{|c|c|c|c|c|c|c|c|c|c|c|c|c|}
\hline DESPESAS & 2015 & AV\% & AH\% & 2016 & AV\% & AH\% & 2017 & AV\% & AH\% & 2018 & AV\% & AH\% \\
\hline Legislativa & 0,00 & 0,00 & 0,00 & $\begin{array}{c}2.372 .11 \\
4,39\end{array}$ & 5,24 & 0,00 & 0,00 & 0,00 & 0,00 & $\begin{array}{c}3.073 .36 \\
3,75\end{array}$ & 6,46 & 0,00 \\
\hline Judiciária & $\begin{array}{c}802.583,9 \\
1\end{array}$ & 2,05 & $\begin{array}{c}100 \\
00\end{array}$ & $\begin{array}{c}317.136 \\
76\end{array}$ & 0,70 & 39,51 & $\begin{array}{c}281.841,3 \\
4\end{array}$ & 0,79 & 35,12 & $\begin{array}{c}678.955 \\
67\end{array}$ & 1,43 & 84,60 \\
\hline $\begin{array}{l}\text { Essencial à } \\
\text { Justiça }\end{array}$ & 0,00 & 0,00 & 0,00 & 0,00 & 0,00 & 0,00 & 0,00 & 0,00 & 0,00 & 0,00 & 0,00 & 0,00 \\
\hline \begin{tabular}{|} 
Administraç \\
ão
\end{tabular} & $\begin{array}{c}5.125 .773 \\
90\end{array}$ & $\begin{array}{c}13,0 \\
7\end{array}$ & $\begin{array}{c}100 \\
00\end{array}$ & $\begin{array}{c}5.228 .06 \\
7,41\end{array}$ & $\begin{array}{c}11,5 \\
4\end{array}$ & 102,00 & $\begin{array}{c}5.030 .627 \\
20\end{array}$ & $\begin{array}{c}14,1 \\
1\end{array}$ & 98,14 & $\begin{array}{c}5.131 .75 \\
4,21\end{array}$ & $\begin{array}{c}10,7 \\
9\end{array}$ & 100,12 \\
\hline $\begin{array}{c}\text { Defesa } \\
\text { Nacional } \\
\end{array}$ & 0,00 & 0,00 & 0,00 & 0,00 & 0,00 & 0,00 & 0,00 & 0,00 & 0,00 & 0,00 & 0,00 & 0,00 \\
\hline \begin{tabular}{|c|} 
Segurança \\
Pública
\end{tabular} & $\begin{array}{c}554.063,2 \\
3 \\
\end{array}$ & 1,41 & $\begin{array}{c}100 \\
00\end{array}$ & $\begin{array}{c}756.534, \\
92 \\
\end{array}$ & 1,67 & 136,54 & $\begin{array}{c}410.398,3 \\
0\end{array}$ & 1,15 & 74,07 & $\begin{array}{c}522.533 \\
43\end{array}$ & 1,10 & 94,31 \\
\hline $\begin{array}{l}\text { Relações } \\
\text { Exteriores }\end{array}$ & 0,00 & 0,00 & 0,00 & 0,00 & 0,00 & 0,00 & 0,00 & 0,00 & 0,00 & 0,00 & 0,00 & 0,00 \\
\hline \begin{tabular}{|c|} 
Assistência \\
Social
\end{tabular} & $\begin{array}{c}2.050 .408 \\
27\end{array}$ & 5,23 & $\begin{array}{c}100 \\
00\end{array}$ & $\begin{array}{c}2.014 .13 \\
4,67 \\
\end{array}$ & 4,45 & 98,23 & $\begin{array}{c}946.114,7 \\
5 \\
\end{array}$ & 2,65 & 46,14 & $\begin{array}{c}431.376 \\
44\end{array}$ & 0,91 & 21,04 \\
\hline $\begin{array}{c}\text { Previdência } \\
\text { Social }\end{array}$ & 0,00 & 0,00 & 0,00 & $\begin{array}{c}2.349 .71 \\
5,34\end{array}$ & 5,19 & 0,00 & 0,00 & 0,00 & 0,00 & $\begin{array}{c}2.760 .95 \\
4,50\end{array}$ & 5,80 & 0,00 \\
\hline Saúde & $\begin{array}{c}11.446 .62 \\
2,20\end{array}$ & $\begin{array}{c}29,1 \\
9\end{array}$ & $\begin{array}{c}100 \\
00\end{array}$ & $\begin{array}{c}11.944 .4 \\
26,25\end{array}$ & 26,36 & 104,35 & $\begin{array}{c}10.614 .60 \\
9,31\end{array}$ & $\begin{array}{c}29,7 \\
6 \\
\end{array}$ & 92,73 & $\begin{array}{c}12.308 .2 \\
85,01\end{array}$ & $\begin{array}{c}25,8 \\
7 \\
\end{array}$ & 107,53 \\
\hline Trabalho & 0,00 & 0,00 & 0,00 & 0,00 & 0,00 & 0,00 & 0,00 & 0,00 & 0,00 & 0,00 & 0,00 & 0,00 \\
\hline Educação & $\begin{array}{c}10.846 .19 \\
7,29\end{array}$ & $\begin{array}{c}27,6 \\
6\end{array}$ & $\begin{array}{c}100 \\
00\end{array}$ & $\begin{array}{c}11.014 .0 \\
36,66\end{array}$ & 24,31 & 101,55 & $\begin{array}{c}9.711 .930, \\
36\end{array}$ & $\begin{array}{c}27,2 \\
3\end{array}$ & 89,54 & $\begin{array}{c}10.703 .2 \\
54,47\end{array}$ & $\begin{array}{c}22,5 \\
0\end{array}$ & 98,68 \\
\hline Cultura & $\begin{array}{c}507.742,3 \\
4 \\
\end{array}$ & 1,29 & $\begin{array}{c}100 \\
00\end{array}$ & $\begin{array}{c}671.736, \\
84 \\
\end{array}$ & 1,48 & 132,30 & $\begin{array}{c}461.407,0 \\
3 \\
\end{array}$ & 1,29 & 90,87 & $\begin{array}{c}649.162 \\
46 \\
\end{array}$ & 1,36 & 127,85 \\
\hline $\begin{array}{l}\text { Direitos da } \\
\text { Cidadania } \\
\end{array}$ & 0,00 & 0,00 & 0,00 & 0,00 & 0,00 & 0,00 & 0,00 & 0,00 & 0,00 & $\begin{array}{c}150.729 \\
76 \\
\end{array}$ & 0,32 & 0,00 \\
\hline Urbanismo & $\begin{array}{c}3.512 .654 \\
06\end{array}$ & 8,96 & $\begin{array}{c}100, \\
00\end{array}$ & $\begin{array}{c}4.440 .86 \\
2,73 \\
\end{array}$ & 9,80 & 126,42 & $\begin{array}{c}3.560 .050 \\
28\end{array}$ & 9,98 & 101,35 & $\begin{array}{c}4.931 .74 \\
6,42 \\
\end{array}$ & $\begin{array}{c}10,3 \\
7 \\
\end{array}$ & 140,40 \\
\hline Habitação & 0,00 & 0,00 & 0,00 & 0,00 & 0,00 & 0,00 & 0,00 & 0,00 & 0,00 & 0,00 & 0,00 & 0,00 \\
\hline Saneamento & $\begin{array}{c}391.863,4 \\
0 \\
\end{array}$ & 1,00 & $\begin{array}{c}100 \\
00\end{array}$ & $\begin{array}{c}454.262, \\
25 \\
\end{array}$ & 1,00 & 115,92 & $\begin{array}{c}554.078,7 \\
2 \\
\end{array}$ & 1,55 & 141,40 & $\begin{array}{c}1.423 .32 \\
2,72 \\
\end{array}$ & 2,99 & 363,22 \\
\hline $\begin{array}{c}\text { Gestão } \\
\text { Ambiental }\end{array}$ & $\begin{array}{c}380.501,1 \\
0\end{array}$ & 0,97 & $\begin{array}{c}100, \\
00\end{array}$ & $\begin{array}{c}386.465 \\
03\end{array}$ & 0,85 & 101,57 & $\begin{array}{c}416.044,1 \\
1 \\
\end{array}$ & 1,17 & 109,34 & $\begin{array}{c}574.653 \\
88 \\
\end{array}$ & 1,21 & 151,03 \\
\hline $\begin{array}{c}\text { Ciência e } \\
\text { Tecnologia }\end{array}$ & 0,00 & 0,00 & 0,00 & 0,00 & 0,00 & 0,00 & 0,00 & 0,00 & 0,00 & 0,00 & 0,00 & 0,00 \\
\hline Agricultura & $38.388,16$ & 0,10 & $\begin{array}{c}100, \\
00\end{array}$ & $17.864,04$ & 0,04 & 46,54 & $43.073,24$ & 0,12 & 112,20 & $\begin{array}{c}66.329,6 \\
4 \\
\end{array}$ & 0,14 & $\begin{array}{c}172 \\
79 \\
\end{array}$ \\
\hline $\begin{array}{l}\text { Organizaçã } \\
\text { o Agrária }\end{array}$ & 0,00 & 0,00 & 0,00 & 0,00 & 0,00 & 0,00 & 0,00 & 0,00 & 0,00 & 0,00 & 0,00 & 0,00 \\
\hline Indústria & 0,00 & 0,00 & 0,00 & 0,00 & 0,00 & 0,00 & 0,00 & 0,00 & 0,00 & 0,00 & 0,00 & 0,00 \\
\hline $\begin{array}{l}\text { Comércio e } \\
\text { Serviços }\end{array}$ & $14.400,00$ & 0,04 & $\begin{array}{c}100 \\
00\end{array}$ & 0,00 & 0,00 & 0,00 & $18.096,00$ & 0,05 & 125,67 & $\begin{array}{c}18.389,8 \\
4 \\
\end{array}$ & 0,04 & 127,71 \\
\hline \begin{tabular}{|c} 
Comunicaç \\
ões
\end{tabular} & $96.517,55$ & 0,25 & $\begin{array}{c}100 \\
00\end{array}$ & $\begin{array}{c}73.779,9 \\
6 \\
\end{array}$ & 0,16 & 76,44 & $60.135,82$ & 0,17 & 62,31 & $\begin{array}{c}69.231,9 \\
3 \\
\end{array}$ & 0,15 & 71,73 \\
\hline Energia & 0,00 & 0,00 & 0,00 & 0,00 & 0,00 & 0,00 & 0,00 & 0,00 & 0,00 & 0,00 & 0,00 & 0,00 \\
\hline
\end{tabular}




\begin{tabular}{|c|c|c|c|c|c|c|c|c|c|c|c|c|}
\hline Transporte & $\begin{array}{c}887.215,9 \\
9\end{array}$ & 2,26 & $\begin{array}{c}100 \\
00\end{array}$ & $\begin{array}{c}690.209 \\
88\end{array}$ & 1,52 & 77,80 & $\begin{array}{c}709.990,9 \\
5\end{array}$ & 1,99 & 80,02 & $\begin{array}{c}655.740 \\
93\end{array}$ & 1,38 & 73,91 \\
\hline $\begin{array}{l}\text { Desporto e } \\
\text { Lazer }\end{array}$ & $\begin{array}{c}263.902,5 \\
5\end{array}$ & 0,67 & $\begin{array}{c}100, \\
00\end{array}$ & $\begin{array}{c}231.723 \\
86\end{array}$ & 0,51 & 87,81 & $\begin{array}{c}327.946,9 \\
5\end{array}$ & 0,92 & 124,27 & $\begin{array}{c}549.462 \\
04\end{array}$ & 1,15 & 208,21 \\
\hline $\begin{array}{l}\text { Encargos } \\
\text { Especiais }\end{array}$ & $\begin{array}{c}2.296 .929,2 \\
9\end{array}$ & 5,86 & $\begin{array}{c}100 \\
00\end{array}$ & $\begin{array}{c}2.344 .88 \\
0,17\end{array}$ & 5,18 & 102,09 & $\begin{array}{c}2.515 .184 \\
80\end{array}$ & 7,05 & 109,50 & $\begin{array}{c}2.874 .31 \\
9,14\end{array}$ & 6,04 & 125,14 \\
\hline $\begin{array}{l}\text { DESPESA } \\
\text { TOT }\end{array}$ & $39.215 .763,2$ & 4100 & 100 & $.307 .951,16$ & 100 & 115,5 & $35.661 .529,1$ & 100 & 90,9 & 47.573.566,2 & 100 & 121,31 \\
\hline
\end{tabular}

Fonte: Autores, 2020.

Durante o período analisado houve uma oscilação tanto positiva quanto negativa na análise vertical das despesas com saúde. Iniciando com 29,19\% o percentual cai para 26,36\% no ano de 2016. Em 2017 sobe novamente para 29,76\%, caindo de novo para 25,87\% em 2018 conforme o Gráfico 10.

Gráfico 10 - Análise Vertical das Despesas na Função Saúde (2014-2017)

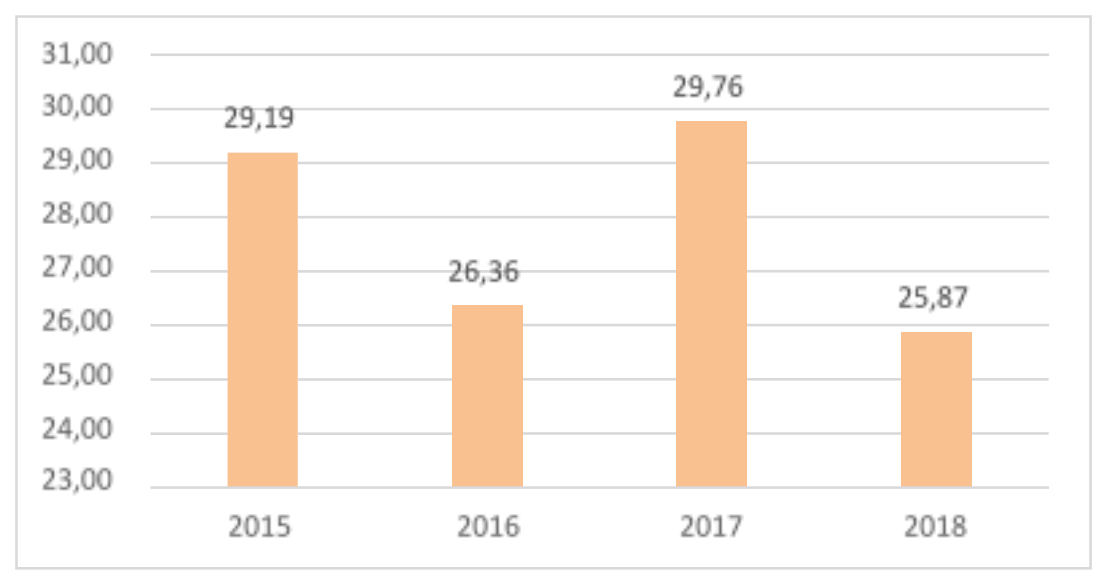

Fonte: Autores, 2020

Para as despesas com educação, o Gráfico 11 apresenta o desempenho. Durante o período analisado, ocorreu o mesmo fenômeno visto na saúde. Primeiro uma queda do ano de 2015 para 2016. Depois uma alta de 2016 para 2017 e novamente uma queda de 2017 para 2018.

Em se tratando de despesas com administração, urbanismo e saneamento, o Gráfico 12 apresenta os resultados. Ocorreu o mesmo tipo de oscilação também com a administração. Já com relação ao urbanismo e o saneamento o percentual foi subindo levemente. 
Research, Society and Development, v. 10, n. 4, e46410414384, 2021

(CC BY 4.0) | ISSN 2525-3409 | DOI: htttp://dx.doi.org/10.33448/rsd-v10i4.14384

Gráfico 11 - Análise Vertical das Despesas na Função Educação (2015-2018)

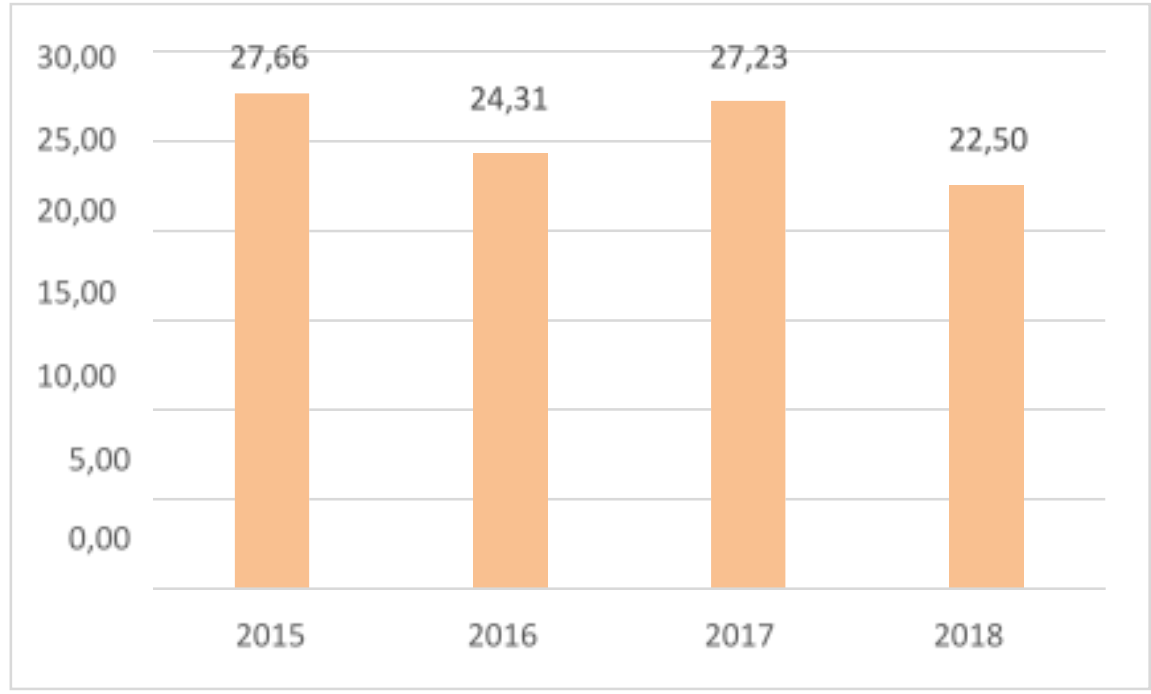

Fonte: Autores, 2020

Gráfico 12 - Análise Vertical das Despesas nas Funções Administração, Urbanismo e Saneamento (2015-2018)

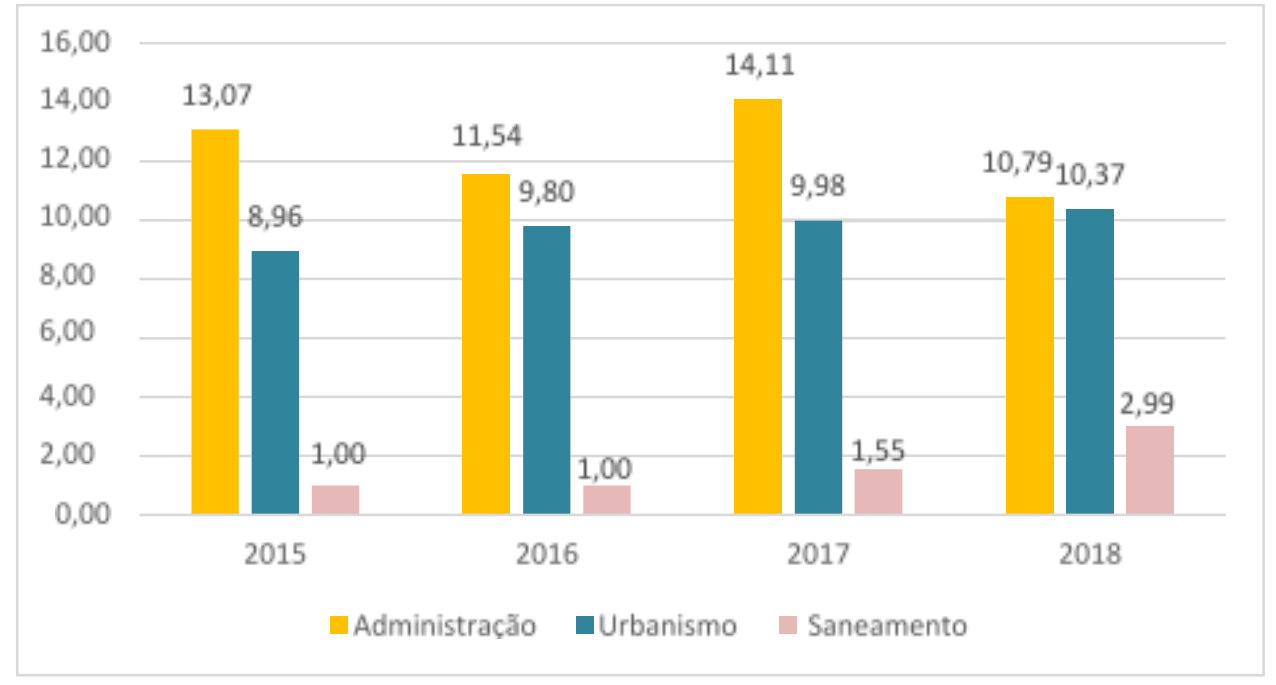

Fonte: Autores, 2020.

Com relação às maiores despesas, o Gráfico 13 apresenta o andamento. Nas três despesas analisadas é possível perceber que houve queda no ano de 2017. Entretanto, todas se recuperaram no ano de 2018. Também é possível perceber que os índices não se alteram de forma brusca. 
Gráfico 13 - Análise Horizontal das Funções Administração, Saúde e Educação (2015-2018)

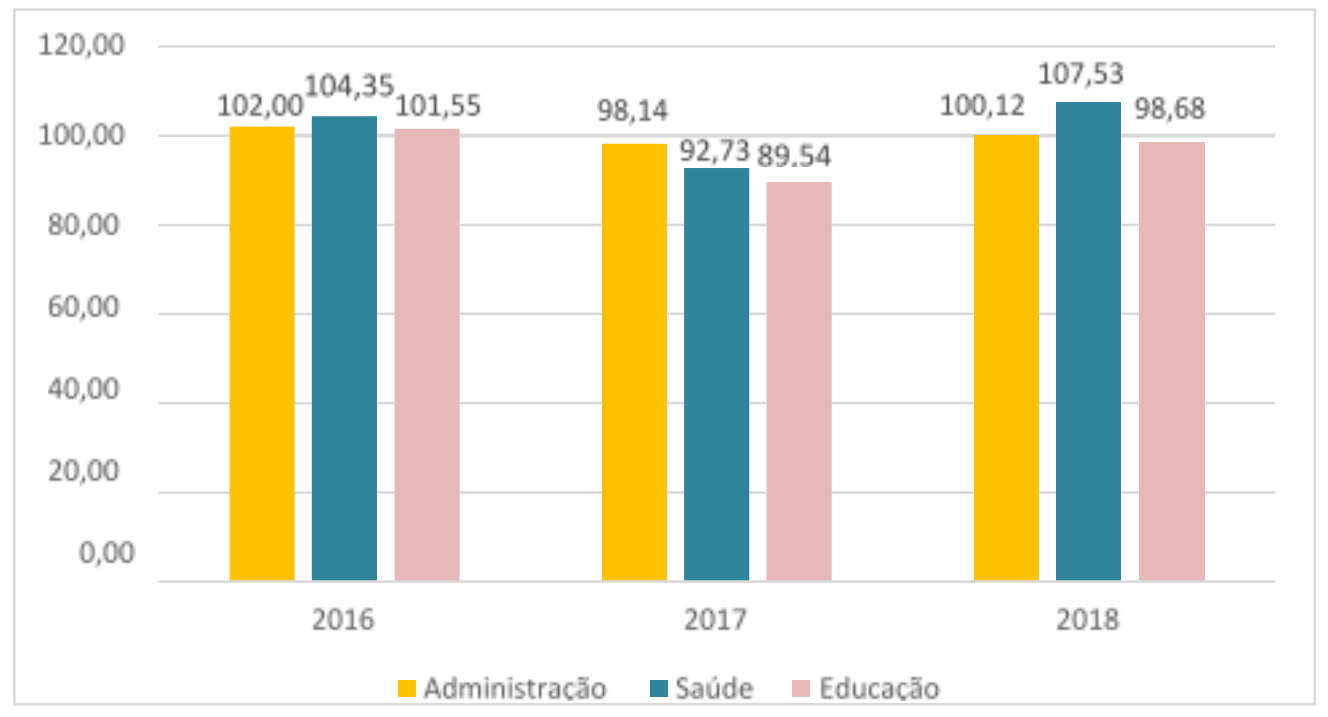

Fonte: Autores, 2020

\subsubsection{Comparação da Distribuição de Receitas e Despesas (2015-2018)}

Através da Tabela 3 pode-se identificar o déficit do município. Com exceção do ano de 2017, todos os anos analisados foram de déficit. No ano de 2017 ocorreu superávit de 8.023.358,33.

Tabela 3 - Comparativo da distribuição das receitas e despesas totais (2015-2018)

\begin{tabular}{|c|c|c|c|c|}
\hline Superávit/Déficit & 2015 & 2016 & 2017 & 2018 \\
\hline 1 - Receita Total & $38.599 .258,16$ & $45.017 .261,24$ & $43.684 .887,49$ & $47.086 .995,87$ \\
\hline 2 - Despesa Total & $39.215 .763,24$ & $45.307 .951,16$ & $35.661 .529,16$ & $48.615 .198,27$ \\
\hline Total (1-2) & $-616.505,08$ & $-290.689,92$ & $8.023 .358,33$ & $-1.528 .202,40$ \\
\hline \multicolumn{5}{|c|}{ Fonte: Autores, 2020. } \\
\hline
\end{tabular}

\subsubsection{Análise dos Balanços Públicos Através dos Índices}

A análise dos balanços públicos através dos índices possibilita a compreensão do desenvolvimento econômico do município com a interação entre diversos tipos de receitas e despesas. A Tabela 4 apresenta o cálculo referente a cada índice e ano analisado. 
Tabela 4 - Índices para análise (2015-2018)

\begin{tabular}{|c|c|c|c|c|c|}
\hline ÍNDICES & FÓRMULA & $\mathbf{2 0 1 5}$ & $\mathbf{2 0 1 6}$ & $\mathbf{2 0 1 7}$ & $\mathbf{2 0 1 8}$ \\
\hline Liquidez Corrente (ILC) & Ativo Financeiro/Passivo Financeiro & 0,87 & 0,78 & 0,41 & 0,19 \\
\hline Liquidez Imediata (ILI) & $\begin{array}{c}\text { Disponibilidades + Vinculados em Conta } \\
\text { Corrente/Passivo }\end{array}$ & 0,74 & 0,75 & 0,39 & 0,16 \\
\hline $\begin{array}{c}\text { Situacão Financeira Líauida } \\
\text { (ISFL }\end{array}$ & $\begin{array}{c}\text { Ativo Financeiro-Passivo Financeiro/Receita Total } \\
\text { (ICD) }\end{array}$ & $-0,01$ & $-0,02$ & $-0,13$ & $-0,49$ \\
\hline $\begin{array}{c}\text { Comprom Dívidas } \\
\text { Grau de Dependência (IGD) }\end{array}$ & Amortização e encargos/Receita Corrente Líquida & 0,06 & 0,05 & 0,01 & 0,02 \\
\hline Estrutura de Capital (IEC) & Receita de Transferências/Receita Corrente & 0,92 & 0,93 & 0,96 & 0,92 \\
\hline Execução da Receita (IER) & Receita Executada/Receita Prevista & 0,59 & 0,69 & 0,78 & 0,72 \\
\hline Equilíbrio Orçamentário (IEO) & Despesa Fixada/Receita Prevista & 1,00 & 1,00 & 1,00 & 1,00 \\
\hline Execução da Despesa (IED) & Despesa Executada/Despesa Fixada & 0,64 & 0,55 & 0,66 & 0,66 \\
\hline Gastos com Pessoal (IGP) & Despesa com Pessoal Total/Receita Corrente \\
Líauida & 0,48 & 0,52 & 0,50 & 0,47 \\
\hline
\end{tabular}

Fonte: Autores, 2020.

\subsubsection{Relatório das Diferenças Entre Receitas e Despesas (2015 a 2018)}

\subsubsection{1 Índice de Liquidez Corrente (ILC)}

O Índice de Liquidez Corrente (ILC) é o índice que indica o quanto o município pode cumprir com suas obrigações utilizando seus próprios recursos sem que faça dívidas ou utilize recursos de terceiros.

O valor de 1,0 representa o índice ideal também referente a 100\%. É possível perceber através da Tabela 4 que o município teve queda constante durante o período analisado, caindo de 0,87 para 0,19 em 2018. Esse valor é considerado como crítico.

Gráfico 14 - Análise através do ILC (2015-2018)

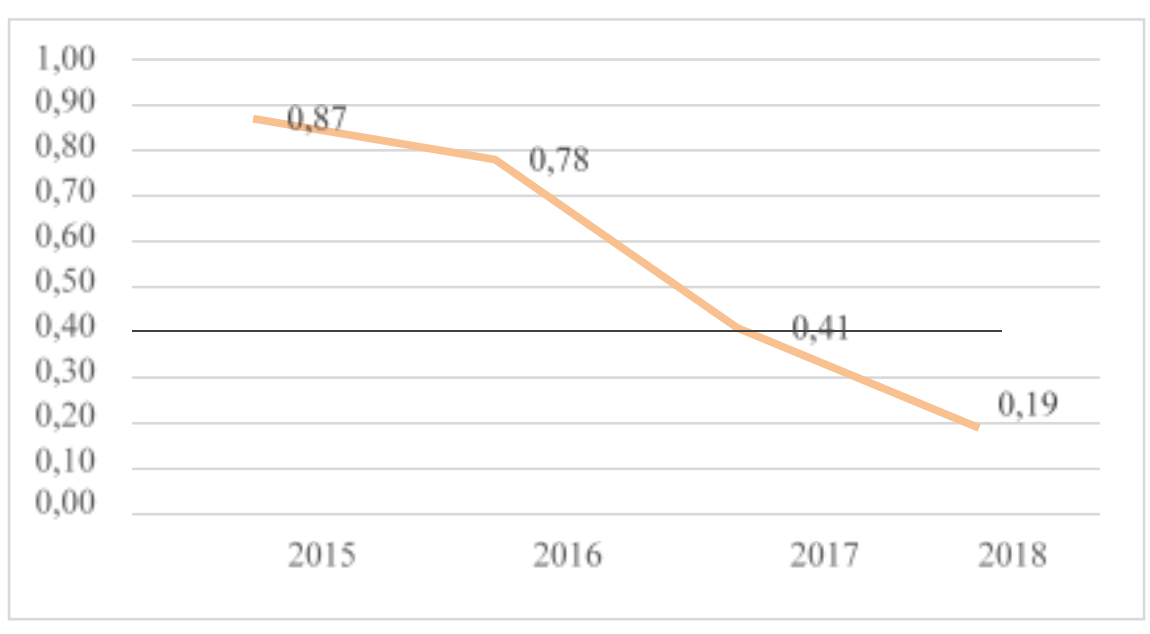

Fonte: Autores, 2020

\subsubsection{2 Índice de Liquidez Imediata (ILI)}

O Índice de Liquidez Imediata (ILI) corresponde à capacidade que o município tem em cumprir com suas obrigações no passivo financeiro através de suas disponibilidades imediatas ou de alta liquidez. 
Através do Gráfico 15 é possível identificar que ocorreu uma leve subida no índice no ano de 2016 de 0,01 e após esse período caiu para 0,16 . Valor esse baixíssimo e extremamente crítico.

Gráfico 15 - Análise através do ILI (2015-2018)

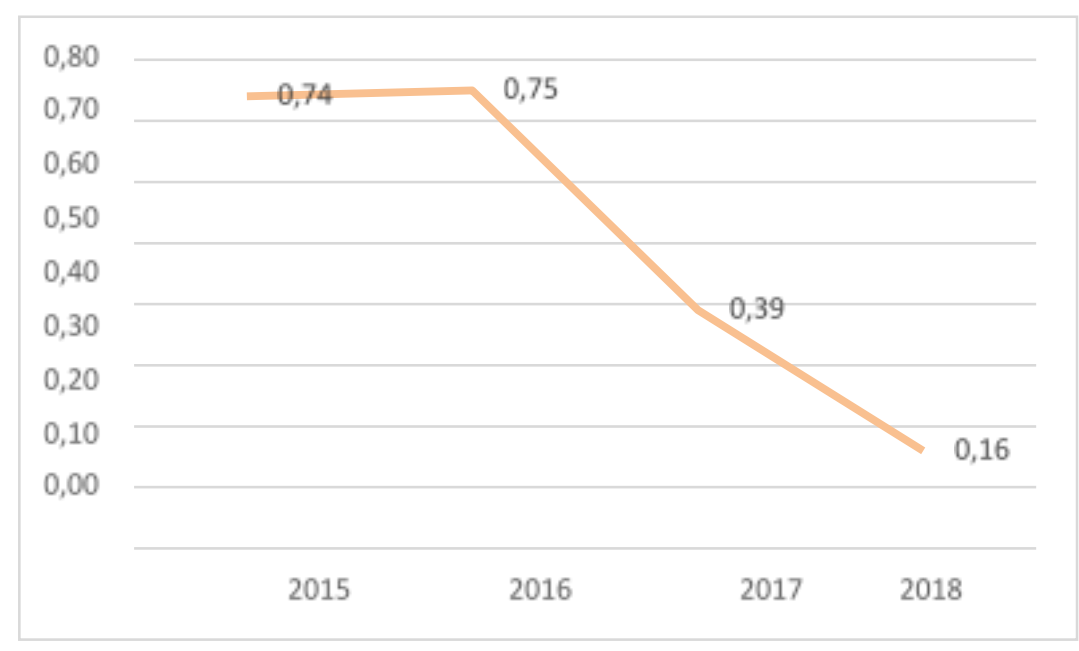

Fonte: Autores, 2020

\subsubsection{3 Índice da Situação Financeira Líquida (ISFL)}

O Índice da Situação Financeira Líquida (ISFL) indica a diferença entre o ativo financeiro e o passivo financeiro relacionado à receita total.

Novamente é registrado uma queda. Inicialmente o índice já estava negativo. Esse índice precisa ser nulo ou positivo. Entretanto, o registrado no município é negativo e ainda está caindo durante o período atingindo -0,49 conforme o Gráfico 16.

Gráfico 16 - Análise através do ISFL (2015-2018)

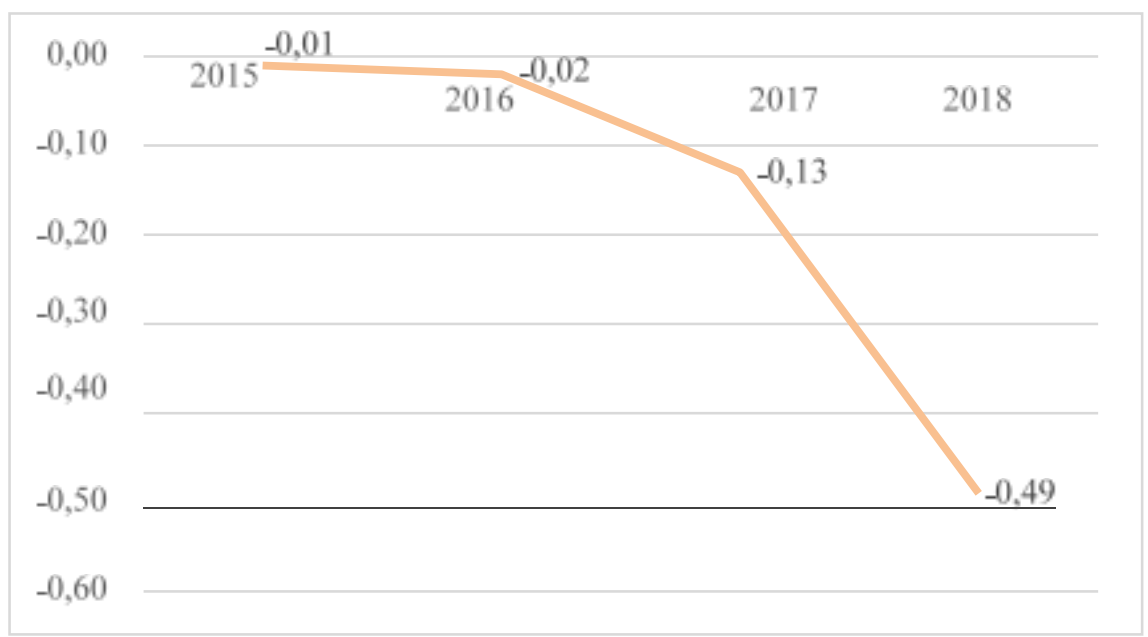

Fonte: Autores, 2020 


\subsubsection{4 Índice de Comprometimento Com Dívidas (ICD)}

O Índice de Comprometimento com Dívidas (ICD) indica o impacto que os encargos e amortizações causam sobre a receita corrente líquida.

O índice registrado está baixíssimo novamente, caindo de 0,06 para 0,01 no ano de 2017 e subindo para 0,02 em 2018 .

Gráfico 17 - Análise através do ICD (2015-2018)

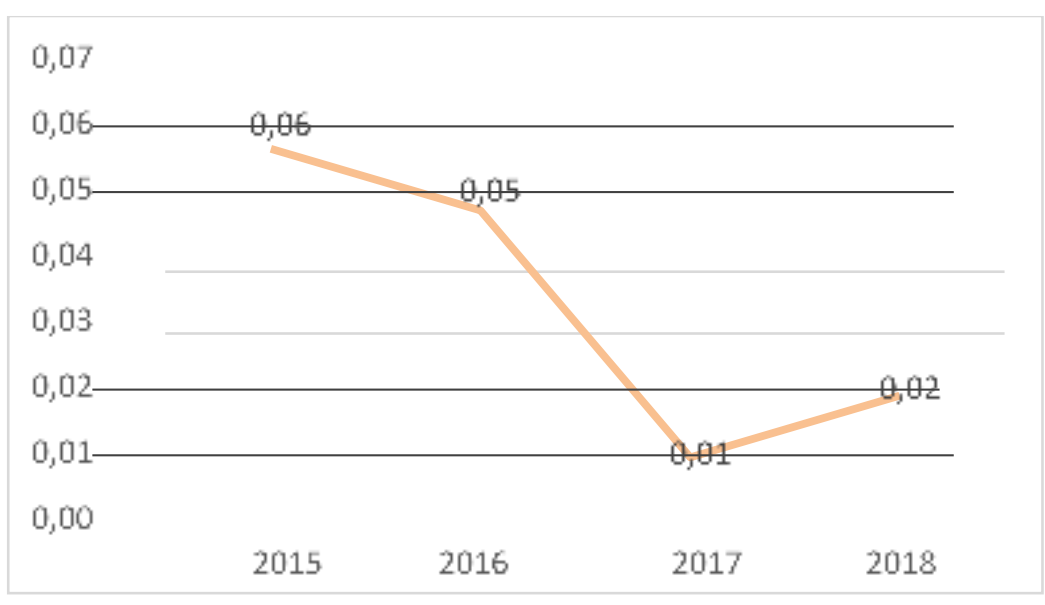

Fonte: Autores, 2020

\subsubsection{5 Índice de Grau de Dependência (IGD)}

O Índice de Grau de Dependência (IGD) indica a dependência da administração pública municipal em relação aos recursos das outras esferas do governo.

É possível identificar pelo Gráfico 18 que o índice aumentou de 2015 para 2017. Entretanto, em 2018 caiu para 0,92 atingindo o mesmo patamar que ocupava em 2015. Esses valores encontrados demonstram a dependência de $92 \%$ de recursos oriundos da União e estado.

Gráfico 18 - Análise através do IGD (2015-2018)

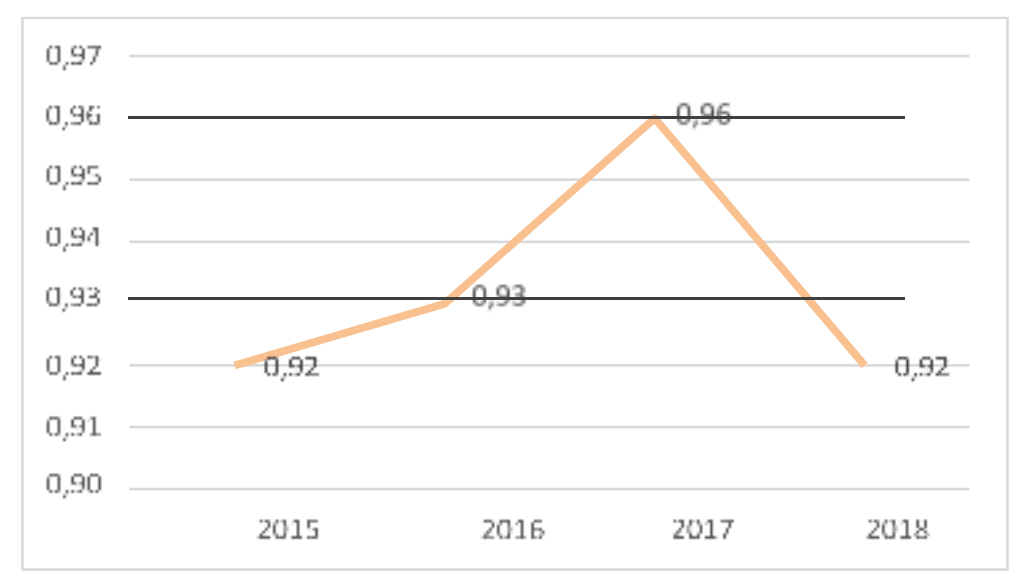

Fonte: Autores, 2020 


\subsubsection{6 Índice de Estrutura de Capital (IEC)}

O Índice de Estrutura de Capital (IEC) indica o quanto terceiros influenciam com seu capital na economia do município. Esse índice demonstra a dependência que o município tem em trabalhar com recursos de terceiros.

É possível identificar pelo Gráfico 19 que ocorre uma leve queda de 2015 para 2016. Após isso ocorre uma subida de 3\%. Em 2018 o índice é fechado em 1,55 considerado como alto.

Gráfico 19 - Análise através do IEC (2015-2018)

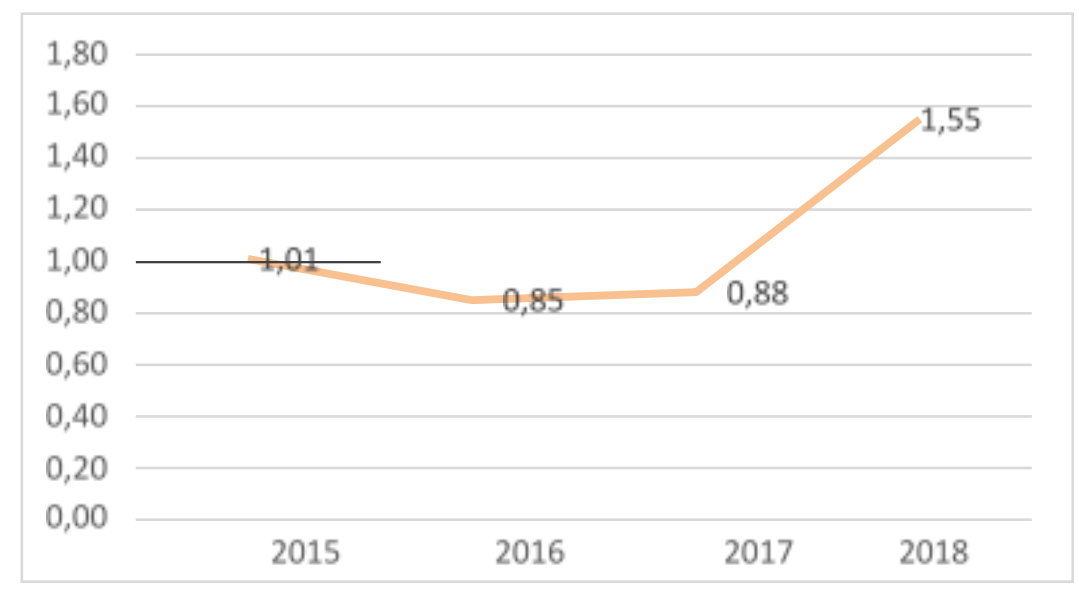

Fonte: Autores, 2020

\subsubsection{7 Índice da Execução da Receita (IER)}

O Índice da Execução da Receita (IER) indica a quantidade de Receita Prevista foi executada. O resultado também deve ser próximo de 1,0 demonstrando que o que foi planejado foi cumprido.

De 2015 a 2017 o índice subiu quase atingindo valores satisfatórios. Entretanto, em 2018 houve queda e o índice fechou em 0,72 conforme o Gráfico 20.

Gráfico 20 - Análise através do IER (2015-2018)

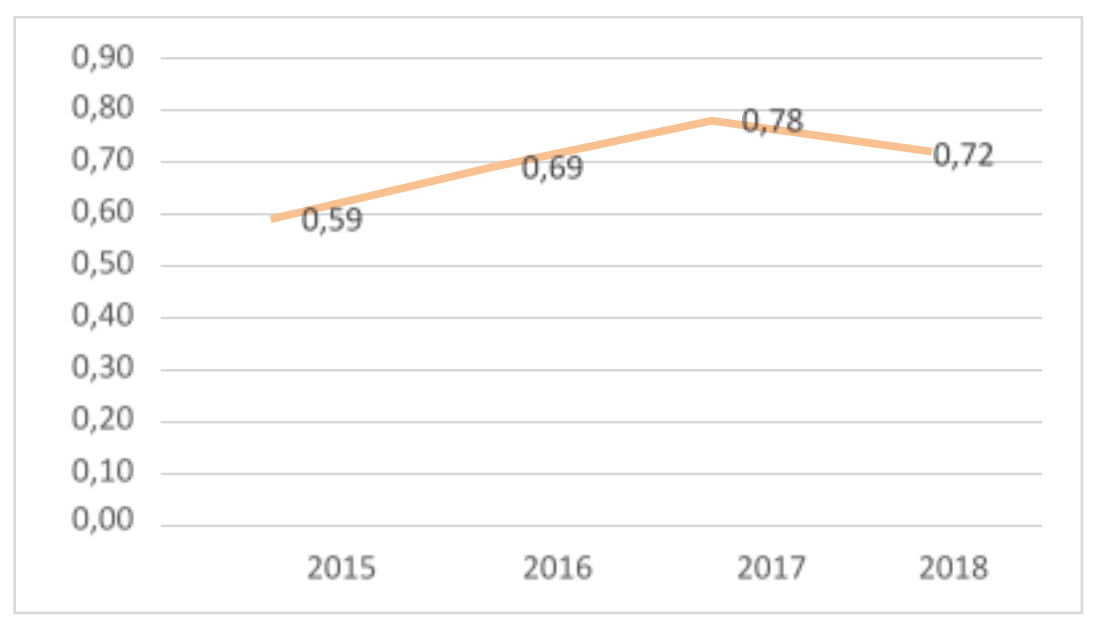

Fonte: Autores, 2020 


\subsubsection{8}

Índice do Equilíbrio Orçamentário (IEO)

O Índice do Equilíbrio Orçamentário (IEO) indica a relação entre a Despesa Fixada e a Receita Prevista. O ideal também é atingir ou ficar mais próximo de 1,0 .

É possível identificar pelo Gráfico 21 que o município não apresentou alterações durante o período analisado, ficando com 1,0 em todo o período.

Gráfico 21 - Análise através do IEO (2015-2018)

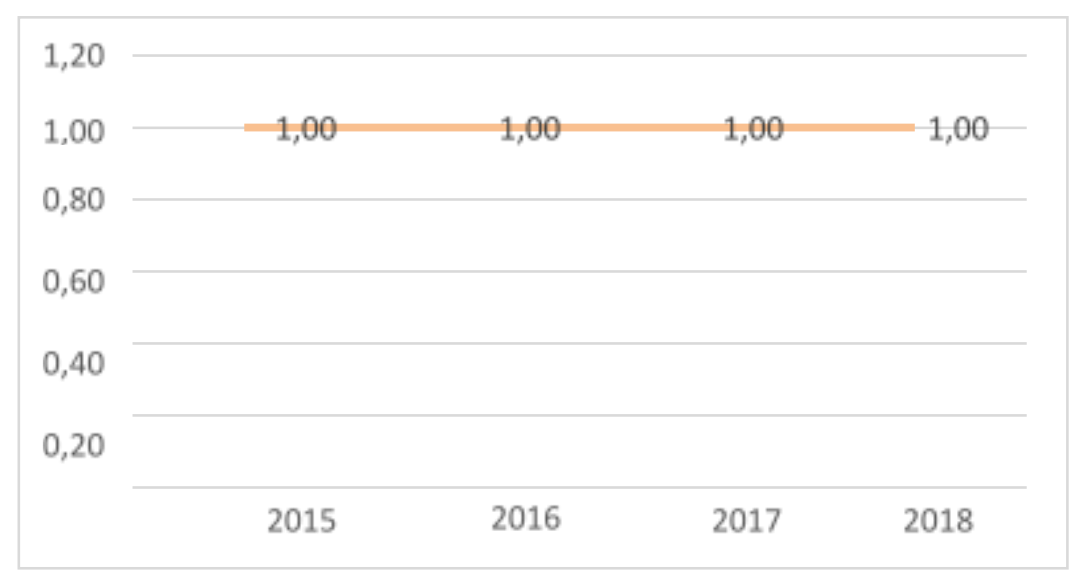

Fonte: Autores, 2020

\subsubsection{9 Índice De Execução Da Despesa (IED)}

O Índice de Execução da Despesa (IED) revela o planejamento do município quanto à fixação e execução das despesas. Esse índice precisa apresentar valores iguais ou menores que 1,0.

Como demonstrado no Gráfico 22, durante o período analisado o município apresentou índices superiores aos aconselháveis. Com leve queda em 2016, os últimos anos apresentaram permanência de 0,66.

Gráfico 22 - Análise através do IED (2015-2018)

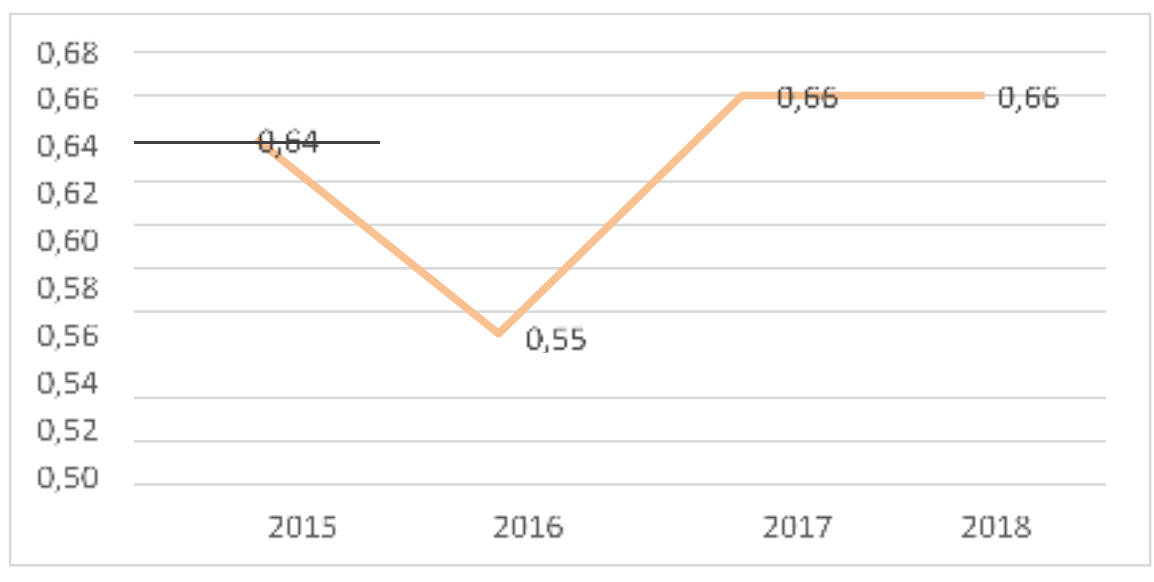

Fonte: Autores, 2020.

\subsection{0 Índice de Gastos com Pessoal (IGP)}

O índice de gastos com pessoal (IGP) consiste em avaliar as despesas com pessoal. De acordo com a LRF o limite máximo é de $60 \%$. 
O valor máximo encontrado de acordo com Gráfico 23 foi de 0,52 ou 52\% no ano de 2016. Depois disso o índice caiu e fechou 2018 em 0,47 demonstrando que o município nesse quesito está dentro da lei.

Gráfico 23 - Análise através do IGP (2015-2018)

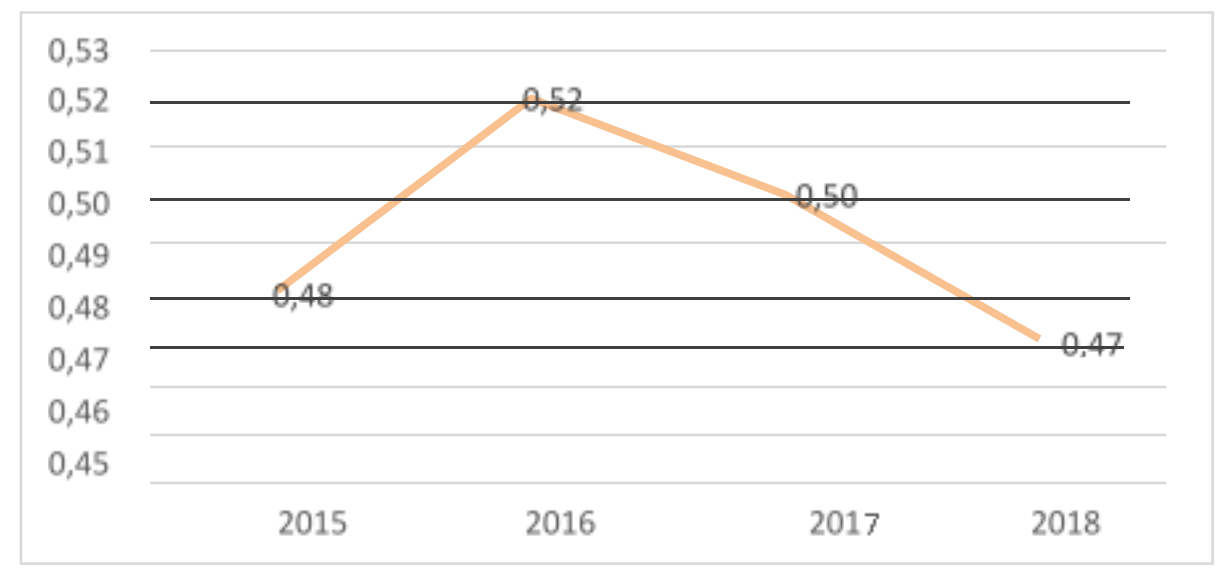

Fonte: Autores, 2020

\subsection{Critérios de Repasse do ICMS para o Município}

A Lei mais conhecida como Lei Robin Hood 13.803/2000, estabelece que alguns recursos deverão ser redistribuídos entre os municípios, como por exemplo 2,5\% do IPI- Exportação e ICMS. Cabe à Lei determinar como se dará a distribuição da parcela da receita do produto de arrecadação do ICMS que será destinada a cada município.

Com o advento dessa Lei, ficou determinado quais seriam os novos critérios para a distribuição da cota-parte do ICMS dos municípios. Essa Lei tem como principal objetivo descentralizar a distribuição da cota-parte do ICMS e por assim conseguir desconcentrar renda transferindo os recursos das regiões mais ricas para as regiões mais pobres. Dessa forma, acredita-se que ocorrerá o incentivo de empenho de recursos em áreas sociais e aumento da arrecadação dos municípios de forma mais eficiente.

\subsubsection{Análise Vertical e Horizontal dos Valores da Cota-Parte do ICMS}

A seguir serão apresentadas as análises verticais e horizontais de acordo com os valores referentes à cota-parte do ICMS.

\subsubsection{Relatório da Distribuição da Cota-Parte ICMS do Município}

O relatório da distribuição da cota-parte ICMS demonstra como o município distribui os repasses em seus setores. A Tabela 5 apresenta essa destinação e as oscilações no período analisado. 
Tabela 5 - Distribuição da cota parte ICMS do município de Rio Acima (2015-2018)

\begin{tabular}{|c|c|c|c|c|c|c|c|c|c|c|c|}
\hline Mês & 2015 & AV\% & 2016 & AV\% & AH\% & 2017 & AV\% & AH\% & 2018 & AV\% & AH\% \\
\hline VAF (R\$) & $\begin{array}{c}16.608 .0 \\
88,71\end{array}$ & $\begin{array}{c}45,0 \\
2\end{array}$ & $\begin{array}{c}18.950 .707 \\
, 63\end{array}$ & $\begin{array}{c}44,9 \\
0\end{array}$ & 114,11 & $\begin{array}{c}20.755 .354 \\
, 52\end{array}$ & 45,41 & 124,97 & $\begin{array}{c}21.316 .0 \\
66,95\end{array}$ & 46,30 & $\begin{array}{c}128,34 \\
7502\end{array}$ \\
\hline $\begin{array}{c}\text { Área } \\
\text { Geográfica }\end{array}$ & $\begin{array}{c}\mathrm{R} \$ 29.79 \\
8,82\end{array}$ & 0,08 & $\begin{array}{c}\mathrm{R} \$ 32.433 \\
81\end{array}$ & 0,08 & 108,84 & $\begin{array}{c}\mathrm{R} \$ 35.669 \\
40\end{array}$ & 0,08 & 119,70 & $\begin{array}{c}\mathrm{R} \$ 34.11 \\
7,33\end{array}$ & 0,07 & $\begin{array}{c}114,49 \\
2218 \\
\end{array}$ \\
\hline População & $\begin{array}{c}\mathrm{R} \$ 98.28 \\
9,96\end{array}$ & 0,27 & $\begin{array}{c}\mathrm{R} \$ 107.25 \\
9,72\end{array}$ & 0,25 & 109,13 & $\begin{array}{c}\mathrm{R} \$ 120.58 \\
8,98\end{array}$ & 0,26 & 122,69 & $\begin{array}{c}\mathrm{R} \$ 113.7 \\
03,75\end{array}$ & 0,25 & $\begin{array}{c}115,68 \\
1958\end{array}$ \\
\hline $\begin{array}{l}\text { População dos } \\
\text { 50mais } \\
\text { populosos }\end{array}$ & . & 0,00 & - & 0,00 & 0,00 & 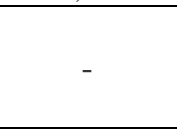 & 0,00 & 0,00 & - & 0,00 & 0 \\
\hline Educação & - & 0,00 & - & 0,00 & 0,00 & $\begin{array}{c}\mathrm{R} \$ 73.308, \\
65\end{array}$ & 0,16 & 0,00 & - & 0,00 & 0 \\
\hline $\begin{array}{c}\text { Produção de } \\
\text { Alimentos }\end{array}$ & $\begin{array}{c}\mathrm{R} \$ 3.523 \\
, 16\end{array}$ & 0,01 & $\begin{array}{c}\mathrm{R} \$ 6.640,9 \\
0\end{array}$ & 0,02 & 188,49 & $\begin{array}{c}\mathrm{R} \$ 6.738,4 \\
4\end{array}$ & 0,01 & 191,26 & $\begin{array}{c}\mathrm{R} \$ 6.837 \\
, 45\end{array}$ & 0,01 & $\begin{array}{c}194,07 \\
1515 \\
\end{array}$ \\
\hline $\begin{array}{c}\text { Mateus } \\
\text { Leme/Mesquita } \\
\end{array}$ & - & 0,00 & - & 0,00 & 0,00 & - & 0,00 & 0,00 & - & 0,00 & 0 \\
\hline $\begin{array}{c}\text { Patrimônio } \\
\text { Cultural }\end{array}$ & $\begin{array}{c}\mathrm{R} \$ 283.8 \\
55,77\end{array}$ & 0,77 & $\begin{array}{c}\mathrm{R} \$ 236.03 \\
9,67\end{array}$ & 0,56 & 83,15 & $\begin{array}{c}\mathrm{R} \$ 156.44 \\
8,51\end{array}$ & 0,34 & 55,12 & $\begin{array}{c}\mathrm{R} \$ 112.6 \\
57,84\end{array}$ & 0,24 & $\begin{array}{c}39,688 \\
4094 \\
\end{array}$ \\
\hline $\begin{array}{c}\text { Meio } \\
\text { Ambiente } \\
(\mathrm{A}+\mathrm{B}+\mathrm{C})\end{array}$ & $\begin{array}{c}\mathrm{R} \$ 229.2 \\
72,29\end{array}$ & 0,62 & $\begin{array}{c}\mathrm{R} \$ 289.61 \\
6,14\end{array}$ & 0,69 & 126,32 & $\begin{array}{c}\mathrm{R} \$ 194.23 \\
1,40\end{array}$ & 0,42 & 84,72 & $\begin{array}{c}\mathrm{R} \$ 218.1 \\
51,41\end{array}$ & 0,47 & $\begin{array}{c}95,149 \\
488\end{array}$ \\
\hline $\begin{array}{l}\text { Programa } \\
\text { Saúde da } \\
\text { Família }\end{array}$ & $\begin{array}{c}\mathrm{R} \$ 46.11 \\
4,50\end{array}$ & 0,13 & $\begin{array}{c}\mathrm{R} \$ 44.477, \\
27\end{array}$ & 0,11 & 96,45 & $\begin{array}{c}\mathrm{R} \$ 52.728 \\
28\end{array}$ & 0,12 & 114,34 & $\begin{array}{c}\mathrm{R} \$ 47.64 \\
3,07\end{array}$ & 0,10 & $\begin{array}{c}103,31 \\
4727\end{array}$ \\
\hline $\begin{array}{l}\text { Saúde per } \\
\text { capita }\end{array}$ & $\begin{array}{c}\mathrm{R} \$ 225.9 \\
57,12\end{array}$ & 0,61 & $\begin{array}{c}\mathrm{R} \$ 251.95 \\
8,64\end{array}$ & 0,60 & 111,51 & $\begin{array}{c}\mathrm{R} \$ 202.68 \\
1,48\end{array}$ & 0,44 & 89,70 & $\begin{array}{c}\mathrm{R} \$ 187.0 \\
19,45\end{array}$ & 0,41 & $\begin{array}{c}82,767 \\
6729\end{array}$ \\
\hline $\begin{array}{l}\text { Receita } \\
\text { Própria }\end{array}$ & $\begin{array}{c}\mathrm{R} \$ 254.2 \\
68,19\end{array}$ & 0,69 & $\begin{array}{c}\mathrm{R} \$ 386.92 \\
1,36\end{array}$ & 0,92 & 152,17 & $\begin{array}{c}\mathrm{R} \$ 378.37 \\
2,54\end{array}$ & 0,83 & 148,81 & $\begin{array}{c}\mathrm{R} \$ 279.3 \\
81,69\end{array}$ & 0,61 & $\begin{array}{c}109,87 \\
6776 \\
\end{array}$ \\
\hline Cota Mínima & $\begin{array}{c}\mathrm{R} \$ 494.8 \\
93,23 \\
\end{array}$ & 1,34 & $\begin{array}{c}\mathrm{R} \$ 538.65 \\
4,33 \\
\end{array}$ & 1,28 & 108,84 & $\begin{array}{c}\mathrm{R} \$ 592.39 \\
0,77 \\
\end{array}$ & 1,30 & 119,70 & $\begin{array}{c}\mathrm{R} \$ 566.5 \\
49,30 \\
\end{array}$ & 1,23 & $\begin{array}{c}114,47 \\
9097 \\
\end{array}$ \\
\hline $\begin{array}{l}\text { Município } \\
\text { Minerador }\end{array}$ & $\mathrm{R} \$ 64,35$ & 0,00 & $\mathrm{R} \$ 62,08$ & 0,00 & 96,47 & $\mathrm{R} \$ 77,02$ & 0,00 & 119,69 & $\mathrm{R} \$ 73,66$ & 0,00 & $\begin{array}{r}114,46 \\
7754 \\
\end{array}$ \\
\hline $\begin{array}{l}\text { Recursos } \\
\text { hídricos }\end{array}$ & - & 0,00 & - & 0,00 & 0,00 & - & 0,00 & 0,00 & - & 0,00 & 0 \\
\hline Penitenciárias & - & 0,00 & - & 0,00 & 0,00 & - & 0,00 & 0,00 & - & 0,00 & 0 \\
\hline Esportes & - & 0,00 & - & 0,00 & 0,00 & - & 0,00 & 0,00 & - & 0,00 & 0 \\
\hline Turismo & $\begin{array}{c}\mathrm{R} \$ 6.383 \\
, 30 \\
\end{array}$ & 0,02 & $\begin{array}{c}\mathrm{R} \$ 11.674, \\
80\end{array}$ & 0,03 & 182,90 & $\mathrm{R} \$ 846,91$ & 0,00 & 13,27 & - & 0,00 & 0 \\
\hline $\begin{array}{c}\text { ICMS } \\
\text { solidário } \\
\end{array}$ & $\begin{array}{c}\mathrm{R} \$ 163.6 \\
68,78\end{array}$ & 0,44 & $\begin{array}{c}\mathrm{R} \$ 179.95 \\
3,96\end{array}$ & 0,43 & 109,95 & $\begin{array}{c}\mathrm{R} \$ 192.49 \\
3,52\end{array}$ & 0,42 & 117,61 & $\begin{array}{c}\mathrm{R} \$ 193.3 \\
26,01\end{array}$ & 0,42 & $\begin{array}{c}118,12 \\
0273 \\
\end{array}$ \\
\hline $\begin{array}{l}\text { Mínimo per } \\
\text { capita }\end{array}$ & - & 0,00 & - & 0,00 & 0,00 & - & 0,00 & 0,00 & - & 0,00 & 0 \\
\hline Subtotal (R\$) & $\begin{array}{c}18.444 .1 \\
78,15 \\
\end{array}$ & $\begin{array}{c}50,0 \\
0\end{array}$ & $\begin{array}{c}21.036 .400 \\
, 26\end{array}$ & $\begin{array}{c}49,8 \\
5\end{array}$ & 114,05 & $\begin{array}{c}22.761 .930 \\
, 40\end{array}$ & 49,80 & 123,41 & $\begin{array}{c}22.982 .6 \\
49,63\end{array}$ & 49,92 & $\begin{array}{c}124,60 \\
6526 \\
\end{array}$ \\
\hline $\begin{array}{l}\text { Compensação } \\
\text { Financeira } \\
\text { (R\$) }\end{array}$ & - & 0,00 & $\begin{array}{c}- \\
129.481,40\end{array}$ & 0,31 & 0,00 & $\begin{array}{c}- \\
181.820,26\end{array}$ & 0,40 & 0,00 & $\begin{array}{c}20.505,3 \\
2\end{array}$ & 0,04 & 0 \\
\hline TOTAL (R\$) & $\begin{array}{l}\mathrm{R} \$ 36.88 \\
8.291,98 \\
\end{array}$ & $\begin{array}{c}100, \\
00\end{array}$ & $\begin{array}{c}42.202 .281 \\
, 97\end{array}$ & $\begin{array}{c}100, \\
00\end{array}$ & 121,60 & $\begin{array}{c}45.705 .681 \\
, 08\end{array}$ & 100,00 & 110,36 & $\begin{array}{c}46.037 .6 \\
72,22\end{array}$ & 100,09 & 103,93 \\
\hline
\end{tabular}

\subsubsection{Relatório De Análise Vertical e Horizontal da Distribuição da Cota-Parte ICMS do Município}

O município de Rio Acima tem recebido repasses que estão aumentando ao longo do tempo. Na totalidade dos repasses, do ano de 2015 para 2016 a parcela aumentou em média R\$6mi. Do ano de 2016 para 2017 esse aumento foi de aproximadamente R \$3mi e de 2017 para 2018 de R \$300mil conforme o Gráfico 24. 
O Valor Adicionado Fiscal (VAF) no período analisado cresceu sucessivamente. Do início ao fim do período avaliado o VAF aumentou seu valor em $\mathrm{R} \$ 5 \mathrm{mi}$ aproximadamente. Essa categoria é a mais representativa entre todos os valores encontrados de acordo com o Gráfico 25.

Gráfico 24 - Repasse total (2015-2018)

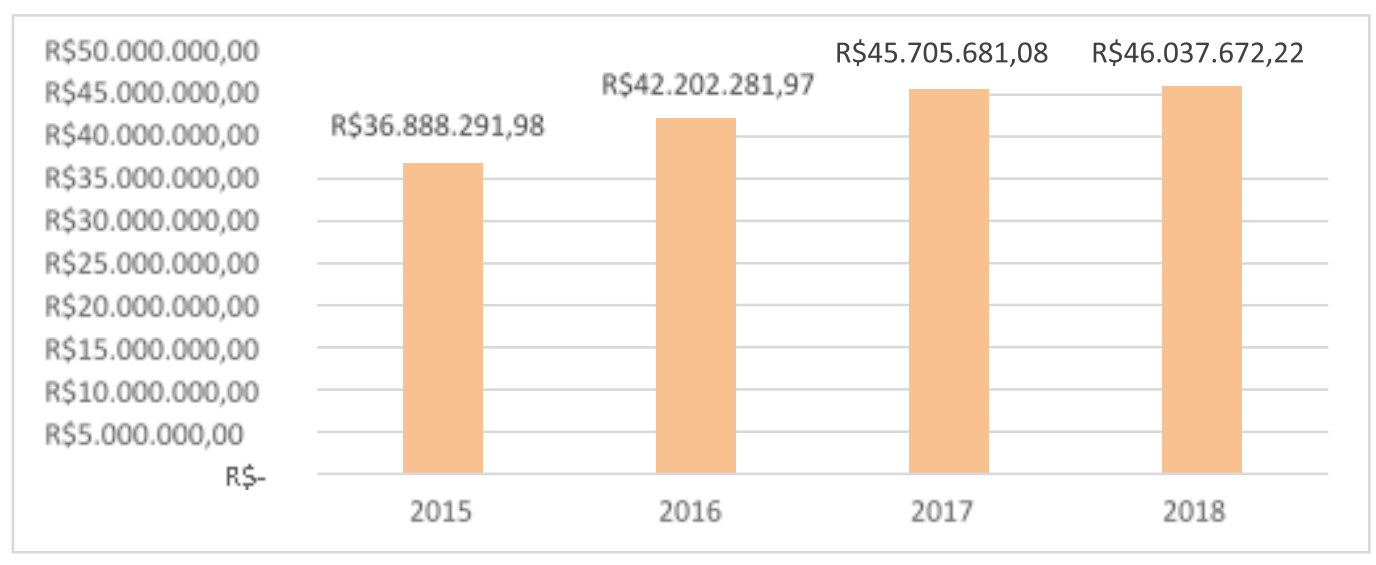

Fonte: Autores, 2020

O Valor Adicionado Fiscal (VAF) no período analisado cresceu sucessivamente. Do início ao fim do período avaliado o VAF aumentou seu valor em $\mathrm{R} \$ 5 \mathrm{mi}$ aproximadamente. Essa categoria é a mais representativa entre todos os valores encontrados de acordo com o Gráfico 25.

Gráfico 25 - Análise Horizontal da cota-parte ICMS (2015-2018)

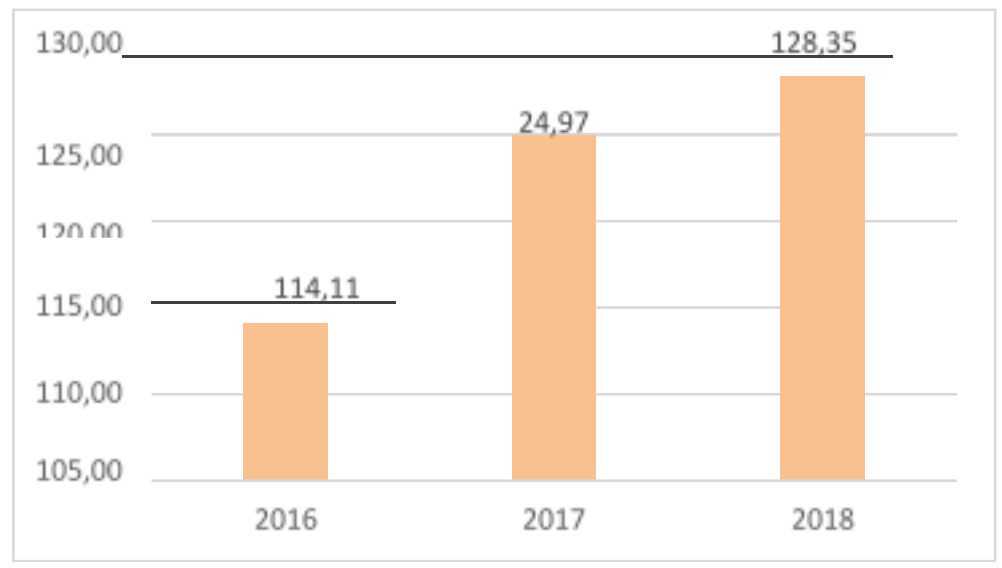

Fonte: Autores, 2020.

Pela análise comparativa do Gráfico 26 podemos perceber que a receita própria, saúde per capita e patrimônio cultural tiveram quedas sucessivas durante o período analisado. O VAF subiu sucessivamente mesmo que de forma tímida e o restante teve leves alterações tanto positivas quanto negativas. 
Gráfico 26 - Análise Horizontal comparativa (2015-2018)

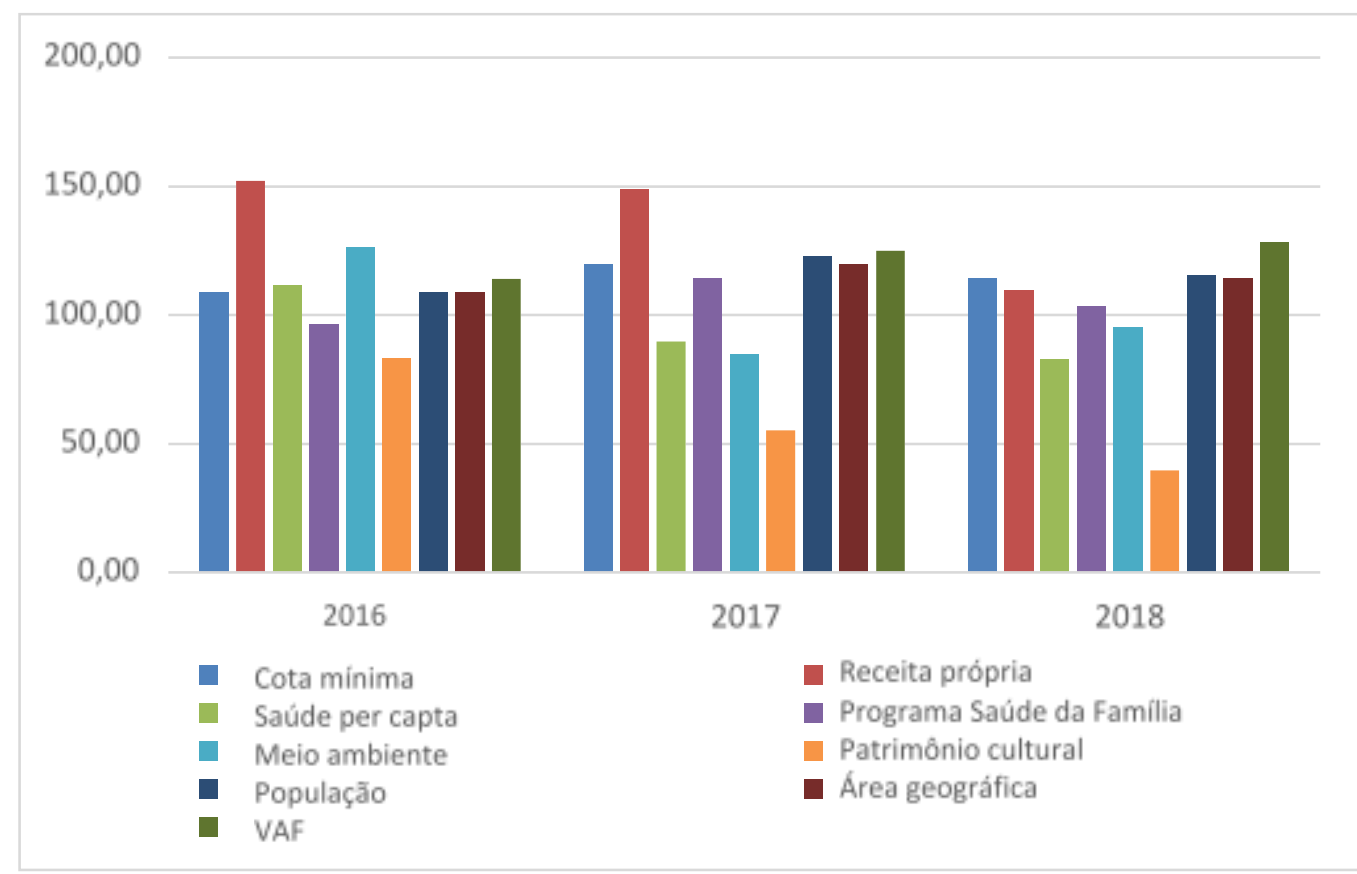

Fonte: Autores, 2020.

Com oscilação positiva e negativa, a cota mínima terminou em 114,48\% em relação ao valor de referência do ano de 2015 como mostra o Gráfico 27.

Gráfico 27 - Análise Horizontal cota-parte cota-mínima (2015-2018)

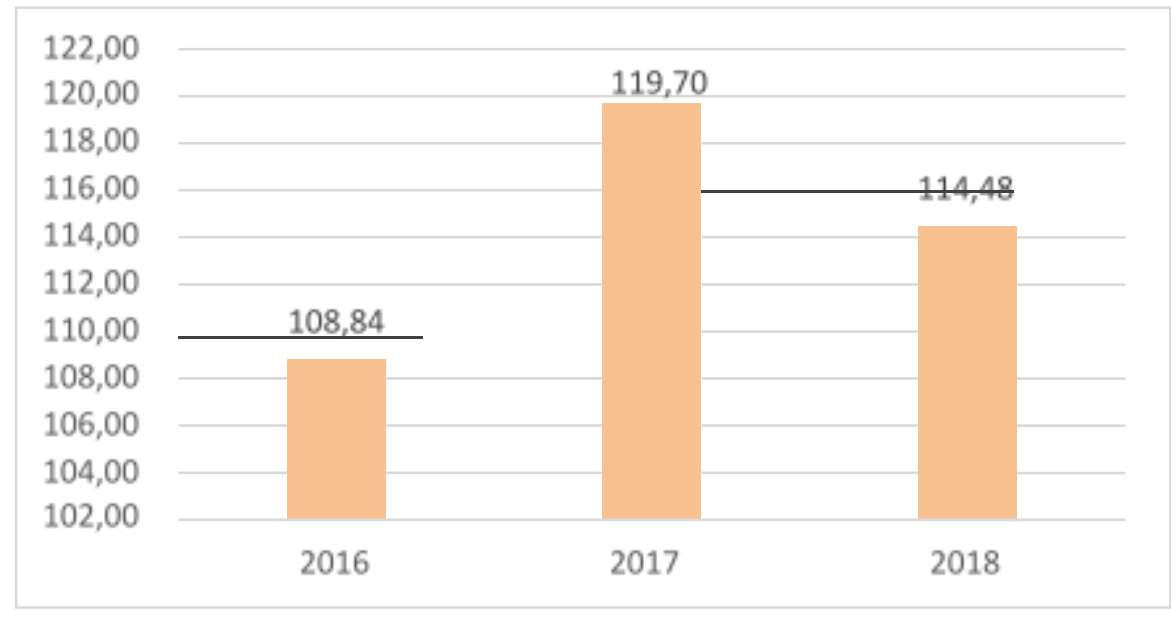

Fonte: Autores, 2019.

Todas as outras categorias se comportaram com pequenas variações durante o período analisado. Após análise, ficou constatado que o município de Rio Acima depende primeiramente do VAF. É dessa categoria que provém a maior quantidade dos recursos utilizados no município.

Alguns autores escreveram sobre a temática apresentada. Aguiar e Souza (2015) elaborou um diagnóstico financeiro do município de Canoas, entre 2012 e 2014, concluindo que no período analisado não houve equilíbrio entre as receitas previstas e as despesas fixadas. Santos e Camacho (2014) consideraram, em seu estudo, a relação entre receitas e despesas visando o equilíbrio orçamentário e consideraram que a prefeitura estudada cumprira com os preceitos legais que norteiam a elaboração 
e execução orçamentaria. Além disso, apontaram que é imprescindível a receita para a execução das despesas e que os responsáveis pela gestão tenham de maneira muito clara o controle entre receita e despesas.

Segundo Lima e Diniz (2016), a condição financeira do município depende do equilíbrio orçamentário, que é a capacidade do governo em gerar receitas para atender suas despesas sem comprometer a liquidez, nem incorrer em déficits ou consumir reservas financeiras.

Segundo Azevedo e Aquino (2016), a dinâmica do planejamento orçamentário em municípios de pequeno porte segue um modelo de orçamento baseado em insumos, sem a atenção devida aos indicadores de desempenho e que isto é reflexo da falta de setores especializados.

Segundo Andrade (2016) as análises das demonstrações contábeis serão extremamente necessárias pela necessidade dos ordenadores de despesa de terem informações mais completas para o planejamento, a execução e a correção de distorções de seus orçamentos.

Dal Vesco et al (2014) elucidam que como os governantes possuem poder sobre as transferências ou dispêndios, é necessário que haja bons indicadores que avaliem a sua eficiência de forma que não comprometa a saúde econômico financeira do município.

\section{Conclusão}

$\mathrm{Na}$ análise dos dados do município, foi possível perceber que assim como os outros municípios pequenos brasileiros, Rio Acima sobrevive prioritariamente de recursos provenientes da União e do estado. Outro ponto comum entre os pequenos municípios é que sua fomentação de receitas é representada em grande maioria por alienação de bens, que é quando acontece leilões onde o município desfaz de bens móveis e imóveis que já se tornaram desnecessários.

Também é possível perceber que existem variações negativas no ano de 2017. Isso pode ser explicado pela crise política e econômica vivida no país nesse período. Mesmo sendo a principal fonte de arrecadação dos tributos, o município sofre com essa categoria. A parcela ainda não é representativa e comparada a outros valores alcança um número insignificante.

A folha com pessoal mostrou-se muito alta. Municípios pequenos muitas vezes possuem a prática de contratar muitas pessoas em relação à quantidade de habitantes de um município. Dessa forma, o município possui muitos funcionários mesmo não sendo todos necessários. As maiores despesas do município seguem o padrão brasileiro, primeiro: saúde e depois educação. Entretanto, não foi possível identificar nenhuma despesa com educação no município levando então a entender que o município não possui nenhuma rede de educação municipal. Provavelmente as escolas do município são estaduais e/ou particulares. Por fim, a execução orçamentária em três anos (2015, 2016 e 2018) registrou déficit, enquanto que 2017 terminou em superávit de $\mathrm{R} \$ 8 \mathrm{mi}$ aproximadamente.

A pesquisa analisou as finanças e aplicação de recursos públicos no município de Rio Acima - MG. Com esse trabalho, a leitura e interpretação dos dados ficam mais fáceis e dinâmicas, de forma que a população ou outros interessados possam entender a dinâmica dos recursos trabalhados no município.

Analisar esses dados dessa forma, melhora o poder de decisão dos gestores municipais que poderão destinar os recursos disponíveis de forma consciente e exata. Como cada município possui uma dinâmica diferente, investindo em setores prioritários de sua região e arrecadando conforme o tamanho e riqueza de seu município, é necessário que os agentes políticos compreendam bem as necessidades e anseios de sua população.

Por outro lado, os cidadãos precisam entender de forma clara essa dinâmica. Só assim poderão acompanhar a destinação dos recursos que o município possui como distribui. Com essa compreensão, poderão cobrar a correta distribuição dos recursos, o atendimento aos anseios da população e exercer o papel de fiscalizadores dos recursos que também são provenientes de impostos pagos pelos próprios cidadãos. 
Como perspectivas futuras, o presente artigo propõe que trabalhos semelhantes sejam realizados, já que o mesmo se mostrou uma importante ferramenta para a gestão municipal, possibilitando a população a entender e cobrar a distribuição de recursos financeiros.

\section{Referências}

Aguiar, J.S \& Souza, A. (2015) Análise do equilíbrio entre as receitas e as despesas do município de Canoas no período de 2012 a 2014 . Trabalho de Conclusão de Curso de Ciências Contábeis/UFRGS. Porto Alegre.

Andrade, N. A. (2016). Contabilidade Pública da Gestão Municipal. (6.ed.). Ed Atlas,

Azevedo, R. R. \& De Aquino, A. C. B. (2016) O planejamento em municípios de pequeno porte em São Paulo. Revista de Contabilidade e Organizações, 10(26), 26, p. 63-76.

Brasil. (1964) Lei Federal n 4.320, de 17 de março de 1964. Estatui Normas Gerais de Direito Financeiro para elaboração e controle dos orçamentos e balanços da União, dos Estados, dos Municípios e do Distrito Federal.

Dal Vesco, D. G. et al (2014) Análise dos indicadores de desempenho em municípios na região Sul do Brasil com até 100 mil habitantes. Enfoque: Reflexão Contábil - UEM. Maringá (PR), 33(2), 19-34, maio/ago.

Faustino, L.G. Planejamento e orçamento público: evolução dos instrumentos de planejamento orçamentário de um município localizado no sul de Minas Gerais. Trabalho de Conclusão de Curso de Administração Pública/UFLA. Lavras.

Fundação João Pinheiro. Lei Robin Hood. Recuperado de: http://www.fjp.mg.gov.br/robin-hood/index.php/leirobinhood.

Gil, A. C. (2008). Como elaborar projetos de pesquisa. (4. ed.). Atlas.

Grzybowski, M; et al. (2016) Orçamento por desempenho: uma análise sobre a relação entre o desempenho da Secretaria de Atenção da Saúde e os recurs os orçamentários alocados em suas ações. Revista Gestão \& Políticas Públicas, 6(2), 213-233.

Instituto Brasileiro de Geografia e Estatística (2018). IBGE Cidades. O Brasil em Síntese. Recuperado de: https://cidades.ibge.gov.br/brasil/mg/rio-acima.

Kohama, H. (2014). Contabilidade Pública: Teoria e Prática, (14ª Ed.), Atlas.

Lima, S.C \& Diniz, J. A. (2016). Contabilidade pública: análise financeira governamental. Atlas.

Linhares, C. L. et al. (2012) A Dinâmica do Equilíbrio Financeiro Municipal e a Lei de Responsabilidade Fiscal. Revista Economia, Brasília, 13(3b),.735-758, set/dez.

Moreira, M. M. (2013). O controle interno como paradigma da Administração Pública gerencial. Jus Navigandi, Teresina, Ano, v. 10.

Peters, B. G (2013). O que é Governança? Revista do TCU, (127), 28-33.

Santos, R. C. L. F. (2012). Orçamento Público.

Santos, L. A. \& Camacho, E. U. (2014) Orçamento público municipal: uma análise no município de Cosmópolis/SP com enfoque no equilíbrio das receitas x despesas no período de 2007 a 2012. Revista Evidenciação Contábil \& Finanças, 2(2), 82-94.

Silva, G. C. et al. (2017) Avaliação de desempenho na gestão pública: análise das oportunidades e potencialidades da literatura internacional. In: I CIDESP_ Congresso Internacional De Desempenho Do Setor Público.

Siconfi - Sistema de Informações Contábeis e Fiscais do Setor Público Brasileiro. Consulta de Declarações. Recuperado de: https://siconfi.tesouro.gov.br/siconfi/index.jsf.

Teixeira, F. M. (2019). Análise do Desempenho Econômico-Financeiro do Município de Sapucaia do Sul no Período de 2015-2018. Trabalho de Conclusão de Curso de Pós-graduação em Administração/UFRGS. Porto Alegre. 